\title{
Review Article \\ Small-Molecule Theranostic Probes: A Promising Future in Neurodegenerative Diseases
}

\author{
Suzana Aulić, ${ }^{1}$ Maria Laura Bolognesi, ${ }^{2}$ and Giuseppe Legname ${ }^{1}$ \\ ${ }^{1}$ Department of Neuroscience, Scuola Internazionale Superiore di Studi Avanzati (SISSA), \\ Via Bonomea 265, 34136 Trieste, Italy \\ ${ }^{2}$ Department of Pharmacy and Biotechnology, Alma Mater Studiorum, University of Bologna, Via Belmeloro 6, 40126 Bologna, Italy
}

Correspondence should be addressed to Giuseppe Legname; legname@sissa.it

Received 17 May 2013; Accepted 3 September 2013

Academic Editor: Roberto Chiesa

Copyright (C) 2013 Suzana Aulić et al. This is an open access article distributed under the Creative Commons Attribution License, which permits unrestricted use, distribution, and reproduction in any medium, provided the original work is properly cited.

\begin{abstract}
Prion diseases are fatal neurodegenerative illnesses, which include Creutzfeldt-Jakob disease in humans and scrapie, chronic wasting disease, and bovine spongiform encephalopathy in animals. They are caused by unconventional infectious agents consisting primarily of misfolded, aggregated, $\beta$-sheet-rich isoforms, denoted prions, of the physiological cellular prion protein $\left(\operatorname{Pr} \mathrm{P}^{\mathrm{C}}\right)$. Many lines of evidence suggest that prions $\left(\mathrm{PrP}^{\mathrm{Sc}}\right)$ act both as a template for this conversion and as a neurotoxic agent causing neuronal dysfunction and cell death. As such, $\operatorname{PrP}^{\mathrm{Sc}}$ may be considered as both a neuropathological hallmark of the disease and a therapeutic target. Several diagnostic imaging probes have been developed to monitor cerebral amyloid lesions in patients with neurodegenerative disorders (such as Alzheimer's disease, Parkinson's disease, and prion disease). Examples of these probes are Congo red, thioflavin $\mathrm{T}$, and their derivatives. We synthesized a series of styryl derivatives, denoted theranostics, and studied their therapeutic and/or diagnostic potentials. Here we review the salient traits of these small molecules that are able to detect and modulate aggregated forms of several proteins involved in protein misfolding diseases. We then highlight the importance of further studies for their practical implications in therapy and diagnostics.
\end{abstract}

\section{Introduction}

Neurodegenerative diseases are a medical, social, and economic problem of paramount importance in developed countries. Besides the fact that their etiology is generally unknown, developing therapeutic and diagnostic interventions for diseases of the central nervous system (CNS) is further complicated by the impermeability of the blood brain barrier (BBB). Thus, Alzheimer's disease (AD) and prion diseases are still not curable with drugs, and only in 2012 [13] positron emission tomography (PET) imaging probes have been included in the $\mathrm{AD}$ diagnostic armamentarium.

In recent years, the close cooperation between drug delivery/treatment and molecular imaging disciplines has resulted in a relatively new branch of knowledge, known as theranostics. The term theranostics was coined to indicate the concomitant therapeutic and diagnostic properties in a single agent. The purpose of theranostics is to optimize the efficacy and safety of therapy, as well as to streamline the entire drug development process. Several exciting examples of theranostic systems have now been reported in the literature for the treatment of cancer [4], atherosclerosis [5], and gene delivery [6], but very few examples are reported in the neuropathological field, especially in the prion field. In our recent work [7] we detailed the development of a small molecule with fluorescent properties that is able to simultaneously detect and inhibit $\mathrm{A} \beta$ and $\operatorname{PrP}^{\mathrm{Sc}}$ plaques in in vitro studies. The progress to date in the design and utilization of these compounds is discussed herein.

\section{Human Prion Diseases}

The term prion (pronounced "pree-on") is the acronym for proteinaceous infectious particle. The prion hypothesis was put forward in 1982 to explain the surprising transmission mechanisms of this unconventional protein $[13,14]$. The discovery that proteins can behave like infectious agents to transmit disease is a milestone in biology. In fact, what sets prions apart, as proposed by Prusiner [14], is that the actual infectious principle consists merely of protein and is capable 
of replicating and transmitting infections without the need for informational nucleic acids. Over the past decade, there has been renewed interest in proteins causing neurodegeneration since they may all act as prions (i.e., amyloid- $\beta, \alpha$ synuclein). This hypothesis has profoundly influenced the development of diagnosis methods and effective therapies for the corresponding diseases.

Prion diseases, also known as transmissible spongiform encephalopathies (TSEs), occur in both humans and animals. Prion diseases are a group of rapidly progressive disorders characterized by a defined spectrum of clinical abnormalities. The number of human and animal diseases recognized as TSEs has increased steadily in recent years. They all share similar hallmarks such as the spongiform degeneration of the brain and variable amyloid plaque formation $\left(\operatorname{PrP}^{\mathrm{Sc}}\right)$. In fact, $\operatorname{PrP}^{\mathrm{Sc}}$ is the disease-associated isoform of the endogenously expressed prion protein $\left(\operatorname{PrP}^{\mathrm{C}}\right)$, which may be present as amyloid deposits. The first cases of human prion disease, Creutzfeldt-Jakob disease (CJD), were reported in the 1920s $[15,16]$. Since then, different forms of human TSEs have been described that can appear as sporadic, inherited, or iatrogenic disorders; they include CJD, Gerstmann-SträusslerScheinker syndrome (GSS), fatal familial insomnia (FFI), and kuru. In animals, several TSEs have been reported, including scrapie in goats and sheep, bovine spongiform encephalopathy (BSE) in cattle, chronic wasting disease in deer and elk, and transmissible mink encephalopathy.

Here we review some crucial points of human prion disorders.

2.1. CJD. CJD presents as a sporadic, hereditary (familial), or acquired (iatrogenic or BSE-related) illness. Approximately $85 \%$ of all CJD cases occur sporadically, geographically, and ubiquitously, with an incidence rate of $0.5-2$ cases per one million people per year. The median age of onset is the seventh decade (64 years) equally affecting men and women [17]. The clinical progression typically occurs over a few weeks. Around $70 \%$ of those afflicted die in less than 6 months. Typically, CJD presents with progressive dementia and cerebellar degeneration, characterized by spongiosis, neuronal loss, astrogliosis, and a clinical syndrome accompanied by dementia, memory loss, ataxia, and myoclonus. Early symptoms, present in approximately one-third of the cases, include fatigue, insomnia, depression, weight loss, headaches, general malaise, and ill-defined pain sensations. In addition to mental deterioration and myoclonus, frequent additional neurological features include extrapyramidal signs, cerebellar ataxia, pyramidal signs, and cortical blindness [18]. Homozygosity for methionine (Met) or valine (Val) at position 129 of the human PrP gene (PRNP) has been identified as a predisposing factor in the majority of sporadic and iatrogenic CJD cases $[19,20]$.

2.2. Familial CJD. Familial CJD (fCJD), representing $5-15 \%$ of all CJD cases, is classified into many haplotypes based on PRNP mutations present in the open reading frame and codon 129 on the mutant allele [21]. The majority of fCJD cases $(>70 \%)$ have been associated with codon 200 mutations
(E200K) [22-24] or with a codon 178 mutation (D178N) in the PRNP gene [25-27]. The symptoms of the familial form of CJD vary depending on the type of PrP mutation involved [28].

2.3. Iatrogenic CJD. Iatrogenic CJD (iCJD) is a very rare disease resulting from neurosurgery, corneal grafting, human dura mater implants, and the use of human growth hormone (hGH) and pituitary derived gonadotropin (hGNH). Iatrogenic CJD was first recognized in 1974 in a US patient who received a corneal transplant from a donor later proven to have died from CJD [29]. Worldwide, at least 226 cases of $\mathrm{iCJD}$, including 26 US cases, have been associated with administration of contaminated human growth hormone (hGH) from cadavers. Of 74 UK cases reported from 1979 till 2011, 65 individuals received human-derived growth hormone, the other 8 individuals received infected dura mater implants, and one case of iCJD was reported after receiving human gonadotropin. In April 2013 one case of probable iCJD was reported (http://www.cdc.gov/eid) after treatment for 23 months with commercial cadaveric hGH when the patient was 6 years old. At the age of 33, 26.5 years (range 25.528 years) after the midpoint of commercial cadaveric hGH treatment, dizziness and gait imbalance developed, causing a fall. Seven months after the fall, he entered a state of akinetic mutism; he died 9 months after symptom onset. A small number of additional cases, known as variant CJD, are caused by secondary infection transmitted by transfusion of blood products. No new sources of disease have been identified, and current practices, which combine improved recognition of potentially infected persons with new disinfection methods for fragile surgical instruments and biological products, should continue to minimize the risk for iatrogenic disease until a blood screening test for the detection of preclinical infection is validated for human use [30].

2.4. Variant CJD. In 1995 and early 1996, a small number of remarkably young CJD patients were diagnosed in the United Kingdom. Due to its similarity to SCJD, this human disease was termed new variant of CJD (vCJD) [31]. In contrast to sCJD, the median age of onset of the disease in vCJD patients is 28 years (sCJD 64 years) and the clinical course is prolonged (median 14 months, sCJD 6 months). The appearance of vCJD in the United Kingdom and the experimental evidence that $\mathrm{vCJD}$ is caused by the same prion strain responsible for BSE raised the possibility of a VCJD epidemic [32, 33]. Laboratory transmission studies in transgenic mice showed that the characteristics of $\mathrm{VCJD}$, including incubation period and neuropathological changes, are very similar in BSE and vCJD [34]. The favored hypothesis for transmission of BSE to humans is a dietary exposure to prion-contaminated bovine tissue (likely CNS) in the 1980s [35]. Variant CJD is difficult to distinguish from other neurological disorders, hence a definitive diagnosis has relied on neuropathology. It has been shown that vCJD can be diagnosed by $\operatorname{PrP}^{\mathrm{Sc}}$ immunostaining on a tonsil biopsy [36]. The majority of vCJD cases have been recognized in individuals homozygous for Met at codon 129 in the PRNP gene [37]. However, Peden et al. reported a case of a patient who was heterozygote at 
codon 129 of PRNP, suggesting that susceptibility to vCJD infection is not confined only to the Met homozygous PRNP genotype [38]. The human genotype at codon 129 of the PRNP gene is known to be a key determinant in human TSEs. This polymorphism modulates phenotype and disease susceptibility to acquired or sporadic prion infection [39]. The large majority of individuals affected by prion diseases are homozygous at codon 129 for either Met or Val [19, 20, 40]. The prevalence of Met/Met is only $39 \%$ in the normal Caucasian population, whereas the frequency for Met/Val is about $50 \%$ and for $\mathrm{Val} / \mathrm{Val} 11 \%$ [19]. In some reports the protective effect of $P R N P$ codon 129 heterozygosity is seen in some of the inherited prion diseases [41, 42].

2.5. GSS. GSS is a rare form of prion disease and occurs at a rate of one per 100 million people per year worldwide [43]. In contrast to CJD, GSS is almost always described in a familial context. Only a few sporadic cases resembling GSS have been reported so far [44]. The syndrome was first described in 1928 by the Austrian neurologist Josef Gerstmann (1887-1969), followed by a more detailed report in collaboration with his colleagues Ernst Sträussler and Ilya Scheinker [45]. Most patients show the first symptoms in the fourth or fifth decade of life. Investigations have shown that missense mutations are present in the PRNP gene of GSS patients. To date, a variety of mutations have been identified, and the most common is at codon 102 (P102L) [46]; others reported are 105 (P105L) [47], 114 (G114V), 117 (A117V) [48], 131 (G131V) [49], 180 (V180I), 187 (H187R), 198 (F198S) [50], 202 (D202N), 212 (Q212P), and 217 (Q217R) [42]. The STOP mutations reported are Y145STOP-129 M [51, 52], Q160STOP, Y226STOP, and Y227STOP [53] (Figure 1). In addition, several insertional mutations have been described that occur in the $\mathrm{N}$-terminal octapeptide repeat region of PRNP $[54,55]$.

2.6. FFI. Fatal familial insomnia (FFI) was first described in 1986 in a 53-year-old man [56]. Since then, it has been reported in several European countries [57-59], Australia [60], and Japan [61]. The occurrence of FFI is associated with the same codon 178 mutation (D178N) also observed in a subtype of familial CJD [62]. The phenotype caused by the D178N mutation depends on a polymorphism at codon 129. The Met 129-Asn 178 allele segregates with FFI, while the Val 129-Asn 178 allele segregates with fCJD [25]. Recently, the first cases of a sporadic form of fatal insomnia (sFI) have been reported in a 44-year-old man and a 58-year-old woman [63-65]. FFI and sFI have similar disease phenotypes. Both disorders have clinical features of disrupted sleep (loss of sleep spindles, slow-wave sleep, and enacted dreams during rapid-eye-movement sleep), autonomic hyperactivation, and motor abnormalities (myoclonus, ataxia, dysarthria, dysphagia, and pyramidal signs). PET shows pronounced thalamic and limbic hypometabolism that become more widespread in later stages. Neuropathological assessment reveals severe neuronal loss and astrogliosis of the anterior medial thalamus and inferior olives, with later cerebral cortical and cerebellar involvement [66].
2.7. Kuru. Kuru ("trembling with fear") is the prototype of human spongiform encephalopathy. It is restricted to the Fore people living in the Eastern Highlands of New Guinea, where prions were transmitted by ritualistic cannibalism [67]. The disease occurred mostly in children and women, because they consumed the brain of deceased family members. In 1959, the local government banned the cannibalistic practice.

\section{Prion Conversion: The "Protein-Only" Hypothesis}

The central molecular event in the replication of mammalian prions is the self-propagating conformational conversion of $\operatorname{PrP}^{\mathrm{C}}$ to the misfolded $\operatorname{PrP}^{\mathrm{Sc}}$ form. This postulate is known as the "protein-only hypothesis" [14]. In recent decades several efforts have been made to understand the mechanism of $\operatorname{PrP}^{\mathrm{C}}$ to $\operatorname{Pr} \mathrm{P}^{\mathrm{Sc}}$ conversion. Two models have been proposed, known as (i) template-directed refolding model and (ii) seedednucleation model.

(i) The template-directed refolding model postulates a direct interaction between $\operatorname{PrP}^{\mathrm{Sc}}$ and $\operatorname{Pr}^{\mathrm{C}}$, which is induced to convert into more $\operatorname{PrP}^{\mathrm{Sc}}$. A high-energy barrier might prevent the spontaneous conversion of $\operatorname{PrP}^{\mathrm{C}}$ to $\operatorname{PrP}^{\mathrm{Sc}}$. In this model the critical step in the conversion is the formation of a dimer between $\operatorname{PrP}^{\mathrm{Sc}}$ and $\operatorname{PrP}^{\mathrm{C}}$ or a partially destabilized folding intermediate of $\operatorname{PrP}^{\mathrm{C}}$ denoted by $\operatorname{PrP}^{*}$. Eventually $\operatorname{PrP}^{\mathrm{Sc}}$ acts as a template that catalyzes the refolding of $\operatorname{PrP}^{\mathrm{C}}$ to a thermodynamically more stable $\operatorname{PrP}^{\mathrm{Sc}}$ conformation (Figure 2(a)).

(ii) The "seeding" or nucleation-polymerization model states that $\operatorname{PrP}^{\mathrm{C}}$ and $\operatorname{PrP}^{\mathrm{Sc}}$ are in a reversible thermodynamic equilibrium. So, only if several monomeric $\operatorname{PrP}^{\mathrm{Sc}}$ molecules (less stable than $\operatorname{PrP}^{\mathrm{C}}$ ) are mounted in a highly ordered seed can more monomeric $\mathrm{PrP}^{\mathrm{Sc}}$ be recruited and eventually aggregated to form amyloid. In such a crystal-like seed, $\operatorname{PrP}^{\mathrm{Sc}}$ becomes stabilized. The rate-limiting step in this mechanism is not the conformational conversion itself but the nucleation step. Fragmentation of $\operatorname{PrP}^{\mathrm{Sc}}$ aggregates increases the number of nuclei, which can recruit more $\operatorname{Pr} \mathrm{P}^{\mathrm{Sc}}$ and thus seems to replicate the agent. In sporadic prion diseases, fluctuations in the local $\operatorname{PrP}^{\mathrm{C}}$ concentration might (exceptionally rarely) trigger spontaneous seeding and self-propagating prion replication (Figure 2(b)).

In this transition, the primary structure of $\operatorname{PrP}$ does not change, but the secondary and tertiary structures in $\operatorname{PrP}^{\mathrm{Sc}}$ are considerably different from those in $\mathrm{PrP}^{\mathrm{C}}$.

3.1. Physiological Functions of $\operatorname{Pr} P^{C}$. It is still unclear whether the toxicity of $\mathrm{PrP}^{\mathrm{Sc}}$ represents a gain of function [68] or whether loss of function of $\mathrm{PrP}^{\mathrm{C}}$ is responsible for neuropathological changes induced by prions [69]. One thing is certain $-\mathrm{PrP}^{\mathrm{C}}$ has to be expressed in $\mathrm{CNS}$ to permit the 

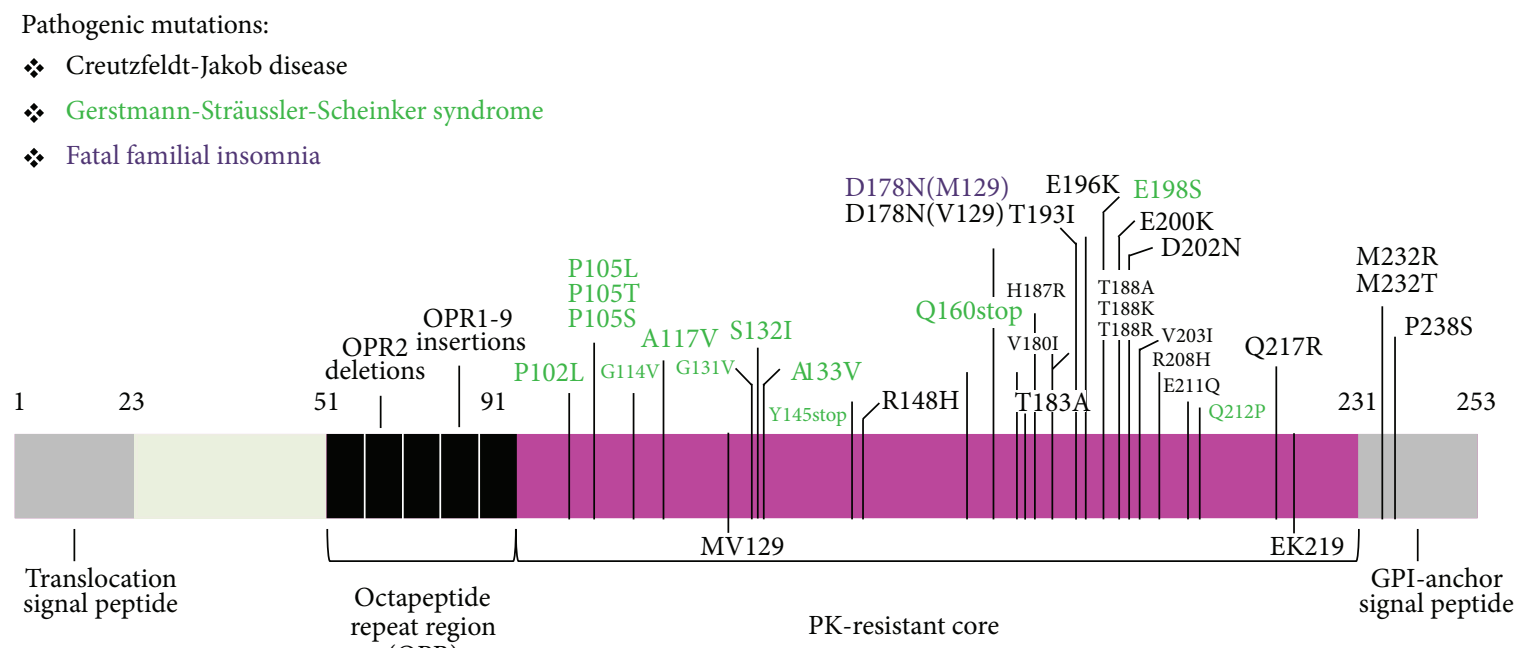

(OPR)

\footnotetext{
Polymorphisms:

* MV129

* EK219
}

FIgURE 1: Pathogenic mutations and polymorphisms in the human PrP. The pathogenic mutations associated with human prion diseases are shown above the human PrP coding sequence. These consist of 1, 2, or 4-9 octapeptide repeat insertions (OPR1-9) within the octapeptide repeat region between codons 51 and 91, a 2 octapeptide repeat deletion (OPR2), and various point mutations causing missense or stop aminoacid substitutions. Point mutations are designated by the wild-type amino acid preceding the codon number, followed by the mutant residue, using single letter amino-acid nomenclature. Polymorphic variants are shown below the PrP coding sequence.
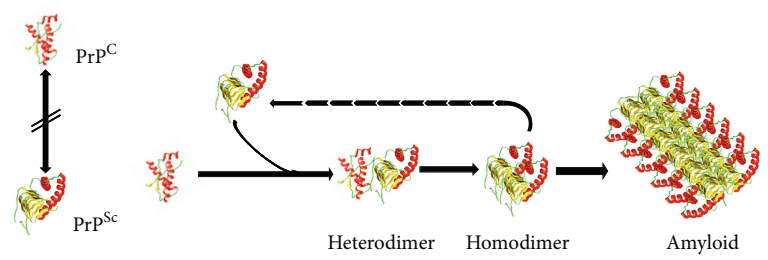

(a)

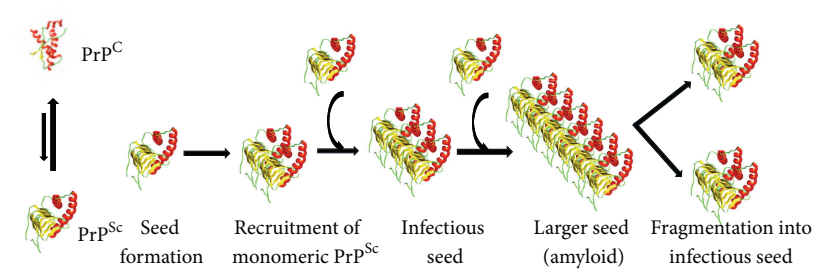

(b)

FIGURE 2: (a) The "template-assistance model" [8] and (b) the "seeding nucleation model" [9].

conversion into $\mathrm{PrP}^{\mathrm{Sc}}$, since the infection of PrP-deficient mice, $\operatorname{Prnp}^{0 / 0}$ [Zürich I] [70] or Prnp ${ }^{-/-}$[Edinburgh] [71], was not successful. As predicted by the protein-only hypothesis, these mice were entirely resistant to prion infections [72]. The ubiquitous presence of $\operatorname{PrP}^{\mathrm{C}}$ supports the notion that $\operatorname{PrP}$ has a generalized cellular function in brain tissue. Several experimental studies [73-75] suggest that $\operatorname{PrP}^{C}$ could play a role in synaptic structure, function, and maintenance. Defining the function of $\mathrm{PrP}^{\mathrm{C}}$ remains one of the main challenges in prion biology, and it is an absolute requirement also for comprehending TSEs attributed to the posttranslational $\operatorname{PrP}^{\mathrm{C}}$ to $\mathrm{PrP}^{\mathrm{Sc}}$ conversion.

The focus of this review is not the physiological form of $\mathrm{PrP}$, rather the pathologic $\mathrm{PrP}^{\mathrm{Sc}}$ scrapie isoform.

\section{Diagnosis of TSEs}

Unfortunately, confirming a clinical diagnosis of TSEs has historically been difficult, as conventional laboratory tests have been ineffective in detecting them. For example, the cerebrospinal fluid most often appears normal, except for an increase in tau and 14-3-3 proteins. Both of these biomarkers support the CJD diagnosis with a sensitivity of $92 \%$ and specificity of 71\% [76]. Brain MRI is increasingly useful in identifying sCJD cases. High signal abnormalities in the basal ganglia and/or cortical ribbon on diffusion weighted imaging (DWI) and fluid attenuated inversion recovery (FLAIR) sequences have recently been added to the diagnostic criteria for probable sCJD (Figures 3(a) and 3(b)) [77]. Moreover, neuroimaging with MRI is useful to exclude other causes of subacute neurologic illnesses. Generally, few imaging abnormalities are seen, for example, generalized atrophy in some cases; in less than $10 \%$ of sCJD cases, hyperintensity of the basal ganglia may be seen in T2-weighted images. In $\mathrm{vCJD}$, putaminal hyperintensity on T2-weighted images is a common finding [78]. In FFI, PET may detect thalamic hypometabolism although in other prion diseases PET generally shows nonspecific cortical hypometabolism. A helpful 


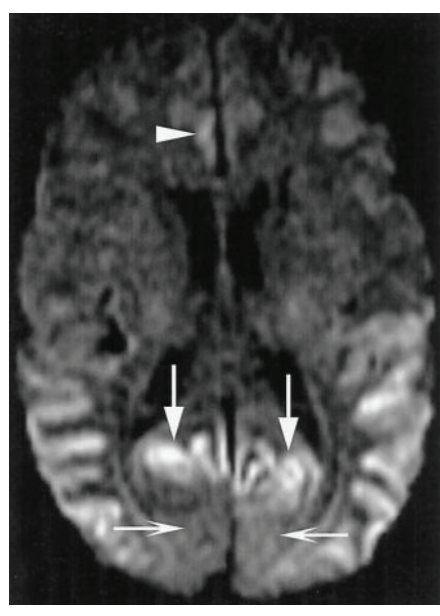

(a)

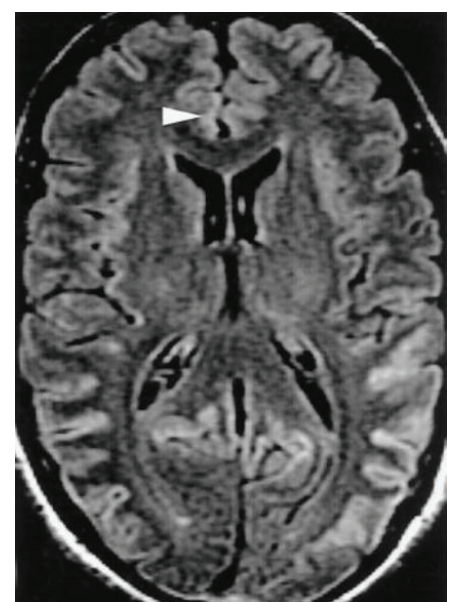

(b)

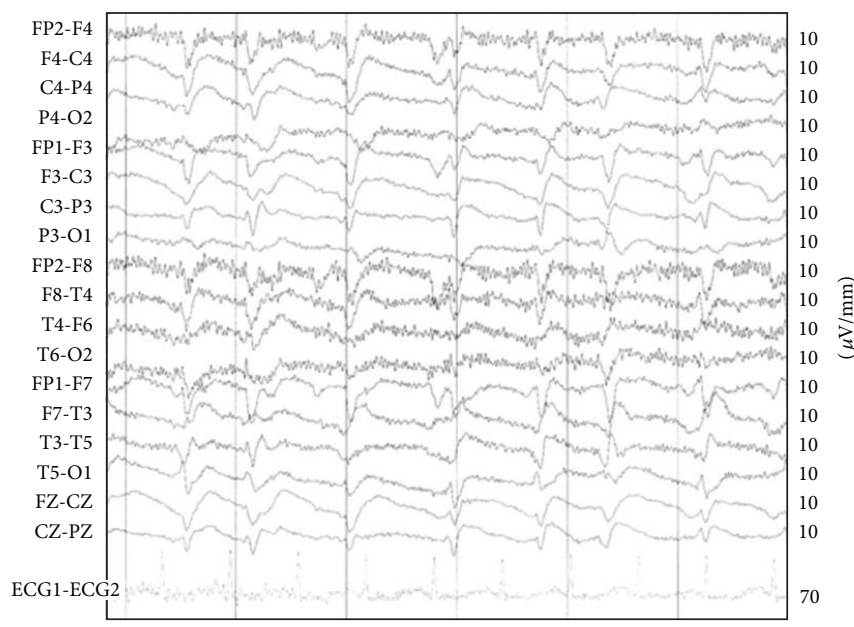

(c)

FIgURE 3: (a) A 50-year-old man with definite sCJD. Axial DWI shows pathologic hyperintensity in bilateral posterior temporoparietal neocortex. Cortex along parietal-occipital fissure is abnormally hyperintense (vertical arrows), but primary visual region is spared (horizontal arrows). Note asymmetric abnormal hyperintensity in right cingulum (arrowhead). Striatum is uninvolved. (b) FLAIR image at same level shows more subtle pathologic hyperintensity in all abnormal regions on DWI, as shown in cingulate cortex (arrowhead) [10]. (c) Definite sCJD (MM1); total duration: 10 months; EEG at 6 weeks: typical (used to classify case as probable); source: http://www.eurocjd.ed.ac.uk.

test is the electroencephalogram (EEG), which measures brain wave activity (Figure 3(c)). The EEG often shows a characteristic abnormal pattern, typically observed in later stages of the disease, but this technique does not confirm a TSE diagnosis. A definite diagnosis of prion disease, as with any dementia, can be made only by pathologic confirmation following biopsy or autopsy. Since the definitive antemortem detection of $\operatorname{PrP}^{\mathrm{Sc}}$ in biopsy specimens is discouraged, because it is invasive and poses risks to health care personnel, unfortunately the last option is autopsy and the analysis of postmortem tissue of infected patients [79].

Prion diseases are generally characterized by widespread neurodegeneration and therefore exhibit clinical signs and symptoms of cognitive and motor dysfunction. In addition, infectious prions propagate by forming amyloid plaques, which are considered as the main hallmark of the disease and serve as a main diagnostic criterion. Since $\operatorname{PrP}^{\mathrm{Sc}}$ is partially resistant to digestion with proteinase $\mathrm{K}(\mathrm{PK})$, this characteristic feature has been used to identify infected samples. Other biochemical characteristics useful to differentiate $\mathrm{PrP}^{\mathrm{C}}$ from $\mathrm{PrP}^{\mathrm{Sc}}$ are insolubility in nonionic detergents and high content of $\beta$-sheet secondary structure. The assays for the detection of $\operatorname{PrP}^{\mathrm{Sc}}$ test brain tissue, where the greatest concentrations of prions are found during the terminal stage of disease. Standard histopathological and immunohistochemical techniques are used to view the tissue microscopically and identify characteristic vacuoles, plaques, or other abnormal features and staining associated with prion diseases. The standard confirmatory test is the Western blot after PK digestion.

4.1. Western Blot. This technique takes advantage of the partial PK resistance of the scrapie form. Treating $\operatorname{PrP}^{\mathrm{Sc}}$ with $\mathrm{PK}$ results in the removal of only 90 amino acids from the $\mathrm{N}$ terminus (Figure 1). The remaining PrP "core" is denoted by 


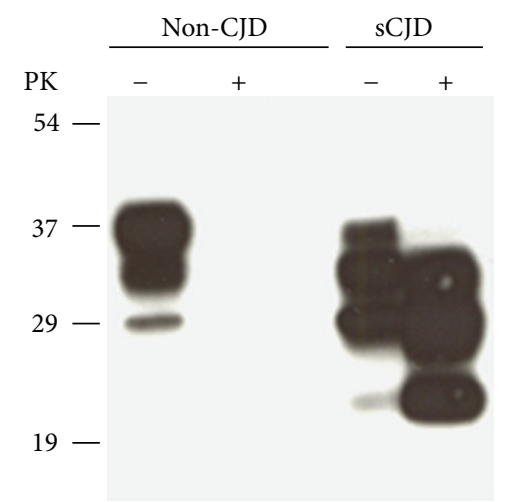

Figure 4: Detection of PK-sensitive $\operatorname{PrP}^{S c}$. (a) Conventional Western blot of PrP treated with or without PK. No PrP was observed after PK treatment in the samples from non-CJD. The PK-resistant PrP27-30 was indicated in the sample from sCJD. Samples were digested with $50 \mu \mathrm{g} / \mathrm{mL}$ proteinase $\mathrm{K}$ for 1 hour at $37^{\circ} \mathrm{C}$, completely hydrolyzing $\operatorname{PrP}^{C}$. Proteinase digestion cleaves $\sim 90$ amino acids from the amino terminus of $\operatorname{PrP}^{\mathrm{Sc}}$ to generate PrP27-30. Blot is developed with anti-PrP mouse monoclonal antibody 3F4 [11].

$\operatorname{Pr} \mathrm{P}^{\mathrm{RES}}$ (PrP, proteinase resistant). Limited protease digestion of $\mathrm{PrP}^{\mathrm{Sc}}$ often produces a smaller, protease-resistant molecule of approximately 142 amino acids, referred to as PrP 27-30. Under the same conditions, $\mathrm{PrP}^{\mathrm{C}}$ and some forms of $\mathrm{PrP}^{\mathrm{Sc}}$ are completely hydrolyzed. Although resistance to limited proteolysis has proven to be a convenient tool for detecting $\operatorname{Pr} \mathrm{P}^{\mathrm{Sc}}$, not all $\mathrm{PrP}^{\mathrm{Sc}}$ molecules are resistant to protease digestion (denoted by sensitive $\operatorname{PrP}^{\mathrm{Sc}}$, $\mathrm{sPrP}^{\mathrm{Sc}}$ ) [80-84]. Figure 4 shows the typical Western blot profile of infected/uninfected and PK digested/PK not digested brain homogenates.

4.2. Conformation-Dependent Immunoassay (CDI). Another test useful for the detection of prions is the conformationdependent immunoassay (CDI). This diagnostic test simultaneously measures specific antibody binding to denatured and native forms of $\operatorname{PrP}$ [82]. In 1998, Prusiner et al. described this assay as not only able to measure very low levels of $\mathrm{PrP}^{\mathrm{Sc}}$ but also capable of discriminating among a wide variety of prion strains. In 2002, the same authors [85] reported that CDI is capable of measuring the disease-causing isoform $\left(\mathrm{PrP}^{\mathrm{Sc}}\right)$ in bovine brainstems with sensitivity similar to that of the endpoint titrations in transgenic ( $\mathrm{Tg}$ ) mice expressing bovine $\operatorname{PrP}(\mathrm{BoPrP})$. Prion titers were $\sim 10^{7} \mathrm{ID}_{50}$ units per gram of bovine brainstem when measured in $\mathrm{Tg}$ BoPrP mice, a figure $\sim 10$ times greater than that determined by bioassay in cattle and $\sim 10,000$ times greater than that determined by bioassay in wild-type mice. This immunoassay provides important information about the tertiary and secondary structure of $\operatorname{PrP}^{\mathrm{Sc}}$, which is strain dependent. Results from CDI should be correlated with those from optical spectroscopic techniques such as time-resolved fluorescence spectroscopy (FRT) and circular dichroism (CD) spectroscopy. The ability to assay features of the tertiary and secondary structure of $\operatorname{PrP}^{\mathrm{Sc}}$ in crude homogenates opens several new areas of investigation, including determination of $\operatorname{PrP}^{\mathrm{Sc}}$ structure in various tissues as well as in different regions of the CNS for a variety of prion strains. In 2005, the sensitivity of the assay was improved by selectively precipitating the $\mathrm{PrP}^{\mathrm{Sc}}$ with $\mathrm{Na}_{2} \mathrm{H}\left[\mathrm{PW}_{12} \mathrm{O}_{40}\right]$ [86].
4.3. Protein Misfolding Cyclic Amplification (PMCA). As reported by several groups, sustained propagation of $\operatorname{PrP}^{\mathrm{Sc}}$ (largely in the CNS) results in the accumulation and deposition of the pathogenic protein. Therefore, the conversion into $\operatorname{PrP}^{\mathrm{Sc}}$ can be reproduced in vitro using a technique named protein misfolding cyclic amplification (PMCA) which was pioneered by Soto and colleagues [87]. PMCA allows propagation of $\mathrm{PrP}^{\mathrm{Sc}}$ in vitro from very small amounts of undetectable seeding material to quantities sufficient for detection by Western blot or plate-based immunoassays. For example, using brain-derived $\mathrm{PrP}^{\mathrm{C}}$ as a substrate, as little as $1 \mu \mathrm{g} / \mathrm{mL}$ of $\mathrm{PrP}^{\mathrm{Sc}}$ can be detected [88]. This ultrasensitive method has been previously applied to identify prions in a wide range of tissue and fluids from scrapie-infected sheep (blood, feces, saliva, and milk) where only small amounts of the infectious agent reside [89-93]. Given its unique ability to detect prions in readily accessible tissue and at preclinical stages of the disease, PMCA is a viable preclinical test for prion diseases.

4.4. Amyloid Seeding Assay (ASA). Back in 2004, Legname et al. [94] reported the production of synthetic prions via in vitro conversion of recPrP [94]. Under different conditions they were able to obtain two different forms of $\beta$ sheet enriched structures $\left(\beta\right.$-oligomer $\operatorname{PrP}^{\mathrm{Sc}}$-like and recPrP aggregates in fibrillar amyloid form). The polymerization process was monitored by simply applying thioflavin (ThT) to the reaction mixture. This dye shows strong increase of fluorescence upon binding to $\beta$-sheet-rich structures like amyloid aggregates. Importantly, in this work authors discovered that the addition of a seed of prefolded amyloid to the fresh reaction substantially shortens the fibrillation process (called lag phase). This experiment shows that recPrP fibrils can be induced by seeding, defining the technique as amyloid seeding assay (ASA). Later in 2007, the authors reported that the ASA detected $\mathrm{PrP}^{\mathrm{Sc}}$, the sole component of the prion, in brain samples from humans with sporadic CreutzfeldtJakob disease as well as in rodents with experimental prion disease [95]. Using the ThT assay, they found that many prion strains are capable of seeding the polymerization of recPrP 
into amyloid, demonstrating that this seeding property can be used as an assay to detect prions in biological samples [95].

4.5. Real-Time Quaking-Induced Conversion Assay (RTQUIC). The development of in vitro techniques, such as PMCA and ASA, has generated the potential for sensitive detection of prions. Quaking-induced conversion assay (QUIC) is another $\operatorname{PrP}^{\mathrm{Sc}}$ amplification assay similar to ASA [96]. This in vitro $\operatorname{PrP}^{\mathrm{Sc}}$ amplification technique employs soluble recombinant $\operatorname{PrP}$ (rPrP-sen) as a substrate, which is seeded with $\operatorname{PrP}^{S c}$ and then subjected to intermittent automated shaking. This technique can be performed more easily than PMCA, which requires repeated sonication. Previous studies have shown that QUIC assays correctly discriminate between normal and scrapie-infected CSF samples in both hamster and sheep prion disease models $[97,98]$. More recently, a more refined QUIC assay, known as real-time quaking-induced conversion assay (RT-QUIC), was designed [99]. RT-QUIC offers sensitivity similar to the in vivo bioassay in hamsters but is roughly 50-200 times faster and much less expensive. RT-QUIC allows the detection of $\geq 1 \mathrm{fg}$ of $\operatorname{PrP}^{\mathrm{Sc}}$ in diluted Creutzfeldt-Jakob disease (CJD) brain homogenate [99]. These findings indicate the promising enhanced diagnostic capacity of RT-QUIC in the antemortem evaluation of suspected CJD [100]. Moreover, Gmitterová et al. reported that the ELISA assay, which measures all 14-3-3 isoforms, was very useful in $\operatorname{PrP}^{\mathrm{Sc}}$ detection [101]; however, this system is not commercially available. Therefore, according to the World Health Organization, diagnosis of prion diseases is usually based on medical history, symptoms (myoclonus, depression), and diagnostic tests, for example, MRI scans and EEGs.

\section{Compounds That Target $\operatorname{PrP}^{\mathrm{Sc}}$}

The presence of $\operatorname{PrP}^{\mathrm{Sc}}$ deposits is considered a hallmark for prion diseases and serves as a main diagnostic criterion. At the same time it represents a therapeutic target for pharmacological intervention. In fact, treatment investigations target mostly the accumulation of $\mathrm{PrP}^{\mathrm{Sc}}$ in the brain. Dozens of drug candidates for TSEs have been reported to date, but only very few proved to be effective in in vivo studies. The two most promising compounds, quinacrine and pentosan polysulphate, have largely been dismissed as ineffective in patients $[102,103]$. A number of compounds have shown antiprion activity in numerous studies using prion inhibitory assays in cell culture [104-107]. These compounds include sulfated polysaccharides, for example, pentosan polysulphate [108], Congo red and other azo dyes [109], amphotericin B and analogues [110], anthracyclines [111], phthalocyanines and porphyrins [112], phenanthridine derivatives [113], inorganic ions, branched polyamines, antagonists of the N-methyl-Daspartate receptor, such as memantine [114], and acridine derivatives, such as quinacrine [115-117]. Immunotherapeutic approaches are also being attempted for prion infection, with various levels of success $[106,118,119]$. In addition, further methods have recently been reported in the screening of large compound collections in vitro $[113,120,121]$.

\section{Diagnosis of Alzheimer's Disease}

Whereas prion diseases are a rare form of neurodegenerative diseases leading to dementia, Alzheimer's disease (AD) is the most common one.

The pathological features of $\mathrm{AD}$ include neuritic plaques composed of amyloid- $\beta$ peptide (A $\beta$ ) fibrils, neurofibrillary tangles of hyperphosphorylated tau (NFT) protein, and neurotransmitter deficits. Although there has been a rapid increase in the understanding of the etiology, genetics, and underlying pathophysiological mechanism for $\mathrm{AD}$ during recent years, there is still no cure for the disease. Therapy is mainly symptomatic as it aims to replace the neurotransmitter deficits. In the quest for disease-modifying treatments, many drug development programs pursue strategies directly related to amyloid or tau. Indeed, these extracellular plaques and deposits of $A \beta$ and intracellular NFT became over the years the pathological hallmark of $\mathrm{AD}$ and drug targets. Despite a robust support for the importance of both, most efforts have focused so far on developing antiamyloid agents to be used in the early stages of the disease. A prerequisite for the early treatment of the disease would be early detection of $\mathrm{AD}$ plaques. Therefore, several strategies have been developed for the imaging of amyloid, namely, radiolabeled amyloid- $\beta$ peptide $(\mathrm{A} \beta)$ antibodies and peptide fragments, small molecules for PET and SPECT imaging, and compounds for MRI.

Several research groups have adopted the small-molecule approach to develop substances suitable for amyloid imaging. Some of the most promising compounds are derivatives of Congo red, thioflavin T, stilbene, and FDDNP. Some of them, like $\left[{ }^{18} \mathrm{~F}\right] \mathrm{FDDNP}$ and $\left[{ }^{18} \mathrm{~F}\right] \mathrm{TZDM}$, have been reported to have affinity for diffuse plaques or $\mathrm{A} \beta_{1-42}$-positive plaques $[122,123]$. Notably, FDDNP has been reported to label also PrP plaques in brain sections [124]. However, these compounds have some limitations in their practical use as probes for in vivo imaging, because of their delayed washout and nonspecific accumulation in the brain white matter [125]. Nonspecific binding of imaging probes leads to high background activity and low contrast images of target structures, resulting in difficult early detection of plaque deposits. Therefore, some basic criteria need to be followed to obtain a small-molecule probe for amyloid plaques (Table 1). Table 1 lists the criteria of an ideal imaging compound for the detection of amyloid in brains of living patients with AD.

The visualization of amyloid plaques in the brains of living patients with $\mathrm{AD}$ would greatly aid the assessment of efficacy for antiamyloid therapy. To date, a number of groups have worked on MRI $[126,127]$ and PET $[12,128,129]$ probes for amyloid plaques. Notably, the PET ligand Pittsburgh compound B ([ $\left.{ }^{11} \mathrm{C}-\right] \mathrm{PIB}$, or 6-OH-BTA-1) has shown promise in early clinical trials and is currently used in a number of human studies [130, 131]. Other groups reported the development of the new near infrared fluorescent (NIRF) ligands for $\mathrm{A} \beta[132,133]$. Due to the short physical half-life of carbon-11 (20.4 minutes), recently, great efforts have focused on the development of $\mathrm{A} \beta$ plaques tracers radiolabeled with fluorine-18, a radioisotope with a considerably longer half-life (109.4 
TABLE 1: Ideal properties for a diagnostic small molecule.

(i) Stable in vivo

(ii) Moderately lipophilic

(iii) Entering the brain in sufficient amounts and retained in the brain

(iv) Low uptake of metabolites to brain

(v) Detection of plaques (imaging properties)

(vi) High specificity for amyloid deposits, low nonspecific bonding

minutes). Some of them, like 4-(N-methylamino)- $4^{\prime}-(2-(2-$ $\left(2-\left[{ }^{18} \mathrm{~F}\right]\right.$ fluoroethoxy)ethoxy)ethoxy)-stilbene ( $\left[{ }^{18} \mathrm{~F}\right]$ BAY $94-$ 9172, florbetaben, with $\mathrm{Ki}=2.22 \pm 0.54 \mathrm{nM})[1,2]$ and 2-(3- $\left[{ }^{18} \mathrm{~F}\right]$ fluoro-4-methylaminophenyl)benzothiazol-6-ol $\left(\left[{ }^{18} \mathrm{~F}\right] \mathrm{GE}-067\right.$, flutemetamol, $\left.\mathrm{Ki}=0.74 \pm 0.38 \mathrm{nM}\right)[3]$, had already been reported under clinical trials. In April 2012, (E)4-(2-(6-(2-(2-(2-[ $\left.{ }^{18} \mathrm{~F}\right]$ fluoroethoxy)ethoxy)ethoxy)pyridin3 -yl)vinyl)-N-methylaniline $\left(\left[{ }^{18} \mathrm{~F}\right] \mathrm{AV}-45\right.$, florbetapir, $\mathrm{Ki}=$ $2.87 \pm 0.17 \mathrm{nM})[134,135]$ had been approved by the US Food and Drug Administration (FDA) as a radioactive diagnostic agent indicated for brain imaging of $\mathrm{A} \beta$ plaques in patients who are being evaluated for $\mathrm{AD}$ and other causes of cognitive impairment. Although autopsy remains the only positive way to diagnose Alzheimer's disease, being able to identify the $\mathrm{A} \beta$ plaques in vivo is a major step forward.

Because the biologic role of $\beta$-amyloid peptides is uncertain, researchers are also investigating alternative targets of intervention at various stages of progression. Ongoing efforts by the research community to qualify biomarkers in clinical trial designs and methods for enriching study populations with patients with early-stage Alzheimer's disease reflect important FDA priorities. Despite our growing understanding of the relationship between various disease-based biomarkers and the clinical course of Alzheimer's disease, it remains unclear whether the effect of a drug on one or more such biomarkers can actually predict a meaningful clinical benefit.

\section{Amyloid Dyes and Their Derivatives}

As mentioned above, candidate probes have primarily been derived from amyloid dyes such as Congo red (CR) and thioflavin T (ThT) [125]. Among all amyloid-staining compounds, CR provides historically the most standardized way of staining amyloid plaques and is still employed in postmortem histological analysis of $\mathrm{AD}$ brains, as the binding is specific [136]. Here we review a few aspects of Congo red, thioflavin $\mathrm{T}$, and their derivatives.

7.1. Congo Red (CR). Congo red (Scheme 1) was invented in 1884 , by the young German chemist Paul Böttiger (Böttiger, P. Deutsches Reichs Patent 28753, August 20, 1884). He created the first "direct" dye that did not require additional substances for fixation to the textile fibers [137]. The mechanism of interaction of CR with amyloid fibrils is not well understood. Some studies suggest that the origin of the specific binding of $\mathrm{CR}$ to amyloid- $\beta$ aggregates is due to the combination of electrostatic interactions between the negatively charged CR's sulfonate groups with the positively charged amino-acid residues in the $\beta$-sheet structures [138, 139]. However, it is even generally believed that CR's binding depends on the secondary configuration of the fibril, consisting predominantly of cross- $\beta$-sheets [140]. Unexpectedly, recent investigations indicate that the dye also possesses the capacity to interfere with processes of protein misfolding and aggregation. This is possible by stabilizing native protein monomers or partially folded intermediates, while reducing the concentration of more toxic protein oligomers [141]. In fact, CR is able to block $\mathrm{A} \beta$ aggregation and toxicity in rat hippocampal neuron culture [142, 143], in HeLa and PC12 cells [144], and in human macrophage culture [145]. Although the effect of CR in transgenic mouse models of $\mathrm{AD}$ has not been investigated so far, CR exerted a positive effect on other experimental models, such as Drosophila melanogaster. Feeding with 5\% $\mathrm{w} / \mathrm{v}$ CR from the embryonic stage resulted in marked survival prolongation, and further histological analysis showed the reduction in the amount of $A \beta$ aggregates and preservation of brain and retinal tissue [146]. Back in 1992, Caughey and Race [147] reported that CR suppresses even $\mathrm{PrP}^{\mathrm{Sc}}$ accumulation and inhibits scrapie agent replication (in interval going from $1.4 \mu \mathrm{M}$ to $42 \mu \mathrm{M}$ ) in cell culture studies (on mouse neuroblastoma cells, $\mathrm{N} 2 \mathrm{a}$ ), showing that the accumulation of $\mathrm{PrP}^{\mathrm{Sc}}$ remained suppressed even after CR removal. In in vivo studies, CR has been observed to exert an ameliorative effect in animals experimentally infected with two different prion strains $(263 \mathrm{~K}$ and $139 \mathrm{H})[148,149]$. Dosages of 0.1 and $10 \mathrm{mg}$ CR (i.p.) did not have any effect, while higher CR dosages (10 mg once a week or $5 \mathrm{mg}$ twice a week) induced a small increase in incubation time in i.c. scrapie-infected mice. A cumulative weekly dose of $75 \mathrm{mg}$ of CR distributed over six days $(12.5 \mathrm{mg})$ had a considerable effect, with incubation times extended almost to 14 days. In the i.p. infected animals, the lower dosages of $1 \mathrm{mg}$ and $10 \mathrm{mg}$ of CR produced a similar extension of incubation time. In a second trial of the same study, CR in dosages of $25 \mathrm{mg}$ per day was given over 6 days, 1 or 2 weeks before inoculation, at the day of infection, or $1,2,3$, or 4 weeks later. The maximal effect was achieved if treatment was initiated on the same day of scrapie infection. Treatments started 2 weeks before or 2 weeks after infection were less effective and almost ineffective if started at 3 and 4 weeks after infection. Thus, the timing of CR treatment is crucial for beneficial effect. On the other hand, other in vitro experiments, either with $\mathrm{A} \beta[150]$ or $\operatorname{PrP}^{\mathrm{Sc}}$ [151], showed that at low concentrations $\mathrm{CR}$ can promote the protein aggregation. Hence, the effect of CR on fibril formation can be either inhibitory or stimulatory depending on its concentration. At low concentrations, CR binding populates generation of partially folded, aggregation-prone forms of proteins (oligomers and protofilament intermediates) resulting in accelerated fibril formation. At higher concentrations, however, CR inhibits fibril arrangement supporting the denatured state, which is much less prone to aggregation. Since CR is toxic (highly carcinogenic due to its benzidine structure) and is not able to cross the $\mathrm{BBB}$, derivatives have been developed and made suitable for antemortem and in 


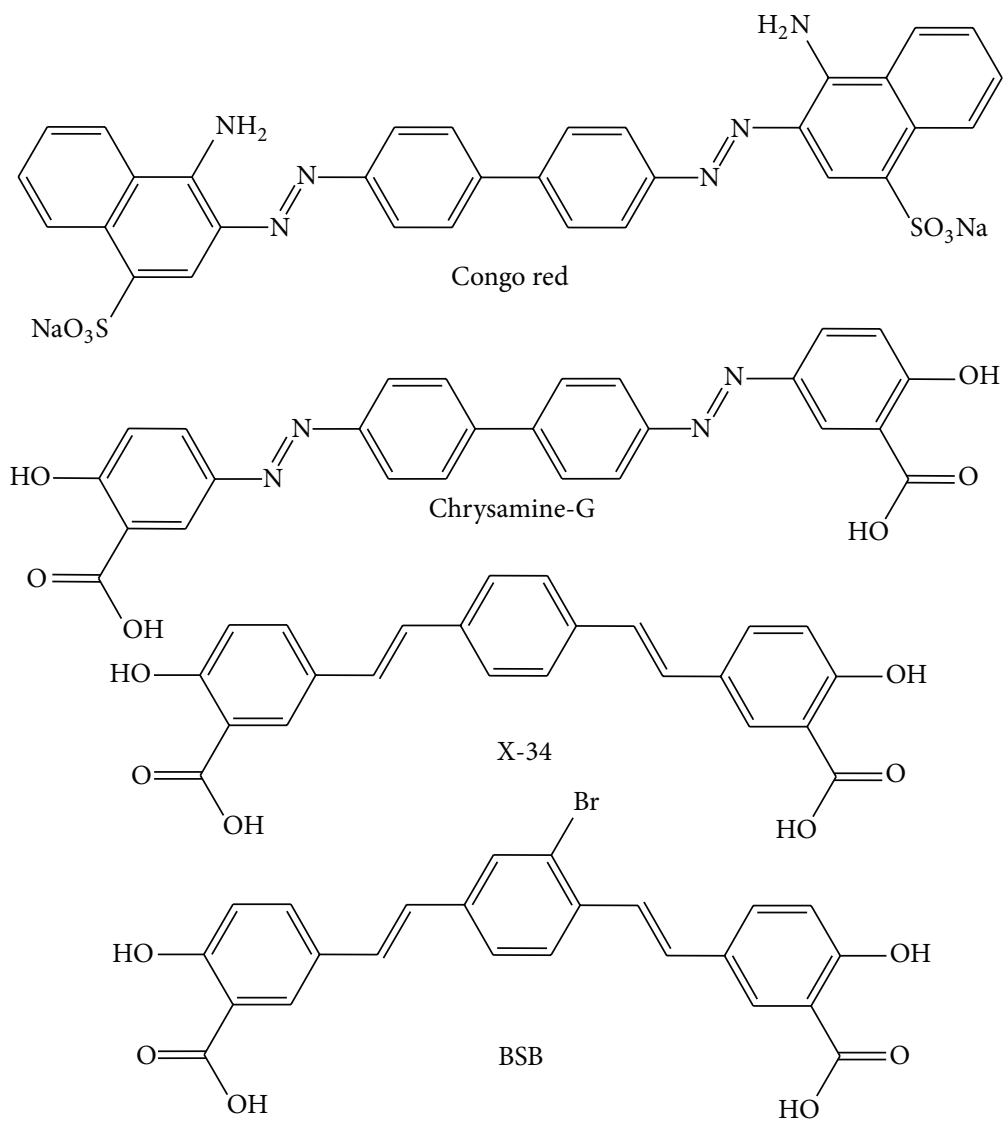

SCHeme 1: Chemical structures of Congo red and its derivatives, potential in vivo imaging agents for $\beta$-amyloid plaques.

vivo visualization and quantification of brain amyloids. Here we report some examples of CR derivatives able to inhibit some of these aggregated proteins. Chrysamine-G, X-34, and $\mathrm{BSB}$ were the most promising derivatives of CR dye.

7.2. Chrysamine-G. Chrysamine-G (CG) is the most intensively examined compound among structural analogues of CR. In this derivative, naphthalenesulfonic acid groups are exchanged for salicylic acid groups with a retained interdistance of 19-20 $\AA$. Its smaller size, as compared to CR, and the higher lipophilicity allow it to cross the intact BBB when injected in a dose of $1 \mathrm{mg} / \mathrm{kg}$ in mice [139]. Most importantly, CG appears to be less toxic than CR, since the administration in vivo $(10 \mathrm{mg} / \mathrm{kg}-100 \mathrm{mg} / \mathrm{kg}$ via i.p.) did not induce any notable behavioral effects in mice during an observation period of up to $72 \mathrm{~h}$ [139]. When incubated with human postmortem brain tissue homogenates, $\left[{ }^{11} \mathrm{C}\right] \mathrm{CG}$ showed the labeling of amyloid angiography and significantly higher binding in the frontal, temporal, and parietal cortices of $\mathrm{AD}$ patients in comparison to those of age-matched controls [152]. CG appeared to be a more potent $\mathrm{A} \beta$ inhibitor than $\mathrm{CR}$, with effective concentrations of the latter being in the range of $2-20 \mu \mathrm{M}$. This finding is in agreement with higher binding affinities of CG than CR to synthetic $\mathrm{A} \beta$ (Ki of $0.37 \mu \mathrm{M}$ and $2.8 \mu \mathrm{M}$, resp.). Chrysamine-G even attenuated $\mathrm{A} \beta_{25-35^{-}}$ induced toxicity in PC12 cells, validated as a decrease in MTT reduction in the concentration range of $0.2-2 \mu \mathrm{M}$ [153].
7.3. X-34. X-34 (1,4-bis-(3-carboxy-4-hydroxyphenylethenyl)-benzene) is a highly fluorescent CG derivative, whose structure consists of a central benzene ring, where the two diazo bonds $(\mathrm{N}=\mathrm{N})$ were replaced by alkene bonds $(\mathrm{C}=\mathrm{C})$. Most importantly, naphthalenesulfonic acids of CR are substituted by salicylic acids; as for CG, this change results in higher lipophilicity and better BBB penetration capacity. This compound has shown promising staining properties of the $\beta$-sheet structures of amyloid plaques and cerebrovascular amyloid in AD autopsy of brain tissue [154].

7.4. BSB. In 2000, Skovronsky and colleagues reported the synthesis of another CR derivative, BSB [(trans, trans)-1-bromo-2,5-bis-(3-hydroxycarbonyl-4-hydroxy)styrylbenzene], demonstrating its high binding affinity for $\mathrm{A} \beta$ aggregates in vitro $(\mathrm{Ki}=0.4 \mu \mathrm{M})[155]$. Like X-34 and CG, BSB specifically labels senile plaques in postmortem $\mathrm{AD}$ brain sections. The authors even observed that BSB permeates living cells in culture and binds specifically to intracellular $\mathrm{A} \beta$ aggregates. After i.c. injection in living transgenic mouse models of $\mathrm{AD}$ amyloidosis, BSB labels plaques composed of $\mathrm{A} \beta$ with high sensitivity and specificity. Lastly, BSB crosses the BBB and labels numerous $\mathrm{AD}$-like plaques throughout the brain of the transgenic mice after i.v. injection. Thus, the authors concluded that BSB is an appropriate starting point for future efforts to generate an antemortem diagnostic tool for AD. In 2004, Ishikawa et al. [156] hypothesized the application of 
BSB in the prion field. The authors found that BSB bound to compact plaques of $\mathrm{PrP}^{\mathrm{Sc}}$, not only in the brain specimens of certain types of human TSEs but also in the brains of TSEinfected mice, when the probe was injected intravenously. The compound was also able to inhibit abnormal $\operatorname{PrP}^{\mathrm{Sc}}$ formation in a cellular model of TSE with $\mathrm{IC}_{50}$ value of 1.4 $\mu \mathrm{M}$. Furthermore, in an additional experimental mouse model, the intravenous injection of $1 \mathrm{mg}$ BSB prolonged the incubation period by $14 \%$ [156]. The efficacy was only observed against the RML strain. Hence, this compound is promising not only as imaging probe but also for therapeutic purposes in TSEs caused by certain strains.

\section{Thioflavin $\mathbf{T}$ (ThT)}

Thioflavin T (ThT) is another dye useful in the analysis of aggregated amyloid proteins (Scheme 2), and it is widely used even to examine fibrillation kinetics in situ. In 1959, Vassar and Culling first described the use of the benzathiole dye thioflavin $\mathrm{T}$ as a potent fluorescent marker of amyloid in histology [157], demonstrating the potential of fluorescent microscopy for amyloid fibril diagnosis. They noted that ThT is selectively localized in amyloid deposits, thereupon exhibiting a dramatic increase in fluorescent brightness. In fact, the binding to amyloid deposits is slightly weaker than with $\mathrm{CR}$ ( $\mathrm{Ki}$ in the sub- and low $\mu \mathrm{M}$ range), but it exhibits a green fluorescence that becomes more than 1000 times brighter upon binding to amyloid plaques [158]. Afterwards, Naiki et al. and LeVine [158-163] were among the first to characterize the fluorescence spectra and binding properties of ThT. They showed that, upon binding of fibrils, ThT displays a dramatic shift of the excitation maximum (from $385 \mathrm{~nm}$ to $450 \mathrm{~nm}$ ) and the emission maximum (from $445 \mathrm{~nm}$ to $482 \mathrm{~nm}$ ) and that ThT fluorescence originates only from the dye bound to amyloid fibrils [159-161]. These studies showed that dye binding is linked to the presence of the cross- $\beta$ structure of fibrils. However, the lack of an atomic resolution structure of amyloid fibrils complicates the elucidation of the binding mode. Unfortunately, ThT possesses the disadvantage of containing a charged group, the positively charged quaternary nitrogen of the benzothiazolium group (Scheme 2), which would likely limit the permeation of the $\mathrm{BBB}$ of this compound. However, the ability of ThT to specifically recognize and bind with modest affinity to amyloid has allowed it to serve as an excellent starting scaffold for derivatization and elaboration to generate a number of amyloid stains and clinical reagents, included for use in medical imaging of amyloid in living patients $[12,164,165]$.

8.1. 6-Me-BTA-0, 6-Me-BTA-1, and 6-Me-BTA-2. In 2001, Klunk et al. [165] showed that removing the charge from ThT affected the amyloid-binding properties of ThT derivatives. In that work the authors reported the synthesis of three ThT derivatives, 6-Me-BTA-0, 6-Me-BTA-1, and 6-Me-BTA-2, all of which were 600 -fold more lipophilic than ThT. They found that the binding to $\mathrm{A} \beta_{1-40}$ fibrils presented higher affinity $(\mathrm{Ki}=20.2 \mathrm{nM})$ than ThT $(\mathrm{Ki}=890 \mathrm{nM})$. These uncharged ThT derivatives stained both plaques and neurofibrillary tangles (NFT) in postmortem AD brain, showing some preference for plaque staining. Furthermore, they examined whether an uncharged, lipophilic derivative of ThT would enter the brain in amounts sufficient for imaging by PET. That compound, designed as [N-methyl- $\left.{ }^{11} \mathrm{C}\right] 6-\mathrm{Me}-\mathrm{BTA}-1$, entered the brain at levels comparable to those commonly used by neuroreceptor imaging agents $(0.223 \% \mathrm{ID}-\mathrm{kg} / \mathrm{g}$ or $7.61 \% \mathrm{ID} / \mathrm{g}$ at $2 \mathrm{~min}$ after-injection) and showed good clearance of free and nonspecifically bound radioactivity in normal rodent brain tissue (brain clearance $t_{1 / 2}=20 \mathrm{~min}$ ). In contrast, the 6-Me-BTA compounds did not display the classic shift in excitation and emission spectra when bound to $\mathrm{A} \beta$ that has been well documented for ThT.

8.2. BTA-1 and 6-OH-BTA-1. One year later, the same group [166] showed that the derivative without the methyl group in position 6 of benzothiazole moiety, denoted by BTA-1 or (2-[4'-(methylamino)phenyl]benzothiazole (Scheme 2$)$, had more promising characteristics than the previously reported compounds. This molecule presented high affinity for the amyloid plaques $\left(\mathrm{Ki}=11 \mathrm{nM}\right.$ for $\left.\mathrm{A} \beta_{1-40}\right)$, and the intravenous injection of [ $\left.{ }^{11} \mathrm{C}-\right]$ labeled BTA-1 in wild type mice resulted in high brain uptake $(12.9 \% \mathrm{ID} / \mathrm{g}$ at $2 \mathrm{~min}$ after-injection). Importantly, $\left[{ }^{11} \mathrm{C}\right] \mathrm{BTA}-1$ is characterized by relatively rapid egress of radioactivity from normal brain tissue. Amyloid deposits were imaged with multiphoton microscopy in the brains of living PS1/APP transgenic mice following the systemic injection of unlabeled BTA-1. The authors concluded that the $\left[{ }^{11} \mathrm{C}\right] \mathrm{BTA}-1$ was a promising radioligand for further development as a PET amyloid-imaging agent for AD.

In 2004, this uncharged ThT derivative was taken into consideration also by Ishikawa et al. as $\operatorname{PrP}^{\mathrm{Sc}}$ inhibitor and as a molecule able to label PrP deposition in TSE brains [156]. Using a well-known $\operatorname{PrP}^{\mathrm{Sc}}$ inhibition assay in cell culture on ScN2a, the authors found that BTA-1 had a promising inhibitory activity $\left(\mathrm{IC}_{50}=4 \mathrm{nM}\right)$ and low toxicity, since no apparent changes were observed up to $10 \mu \mathrm{M}$ of treatment. Next, they assessed its utility as diagnostic imaging tool for PrP plaques using the histopathological specimens from human TSE cases. They found that it was able to fluorescently label most of the PrP plaques in the cerebral cortices of GSS cases and of variant CJD cases, whereas it was not able to stain PrP plaques of sporadic CJD cases. Similar results were observed when the postmortem brains of Tg7 mice infected with the $263 \mathrm{~K}$ strain were used, considering that it stained the plaque type of $\operatorname{PrP}$ in the cerebral white matter between cortex and hippocampus. Due to the absence of positive charge and its capability to cross the BBB, they even performed in vivo experiments using $\mathrm{Tg} 7$ mice infected with $263 \mathrm{~K}$ strain. A bolus injection of BTA-1 labeled PrP plaques in the white matter between cortex and hippocampus of the affected brains. Faint cerebrovascular labeling was occasionally observed at $4 \mathrm{~h}$ after the injection, but not at $18 \mathrm{~h}$ or later. Moreover, no significant labeling was observed in uninfected transgenic mice. Similar results were observed in Tga20 mice infected with RML strain, although labeled PrP plaques were less frequently observed. Even the 6-hydroxy BTA-1 derivative (also called PIB or 6-OH-BTA-1) inhibited $\mathrm{PrP}^{\mathrm{Sc}}$ formation in $\mathrm{ScN} 2 \mathrm{a}$ cells with an $\mathrm{IC}_{50}$ in the nanomolar 


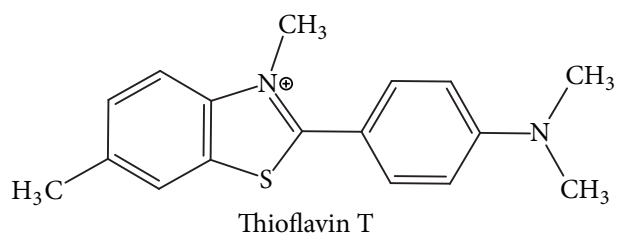<smiles>CNc1ccc(-c2nc3ccc(C)cc3s2)cc1</smiles><smiles>Cc1ccc2nc(-c3ccc(N(C)C)cc3)sc2c1</smiles><smiles>Cc1ccc2nc(-c3ccc(N)cc3)sc2c1</smiles>

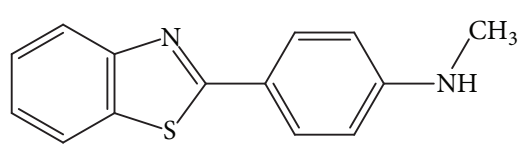

BTA-1

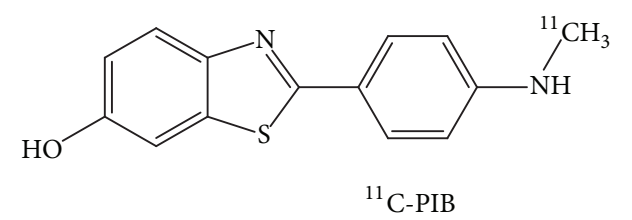

Scheme 2: Chemical structures of thioflavin $\mathrm{T}$ and its derivatives, useful for potential in vivo imaging for $\beta$-amyloid plaques.

range; more importantly, it has been selected for the first human trial of a benzothiazole amyloid-imaging agent [131]. In their latter report, Rowe et al. analyzed 16 patients with diagnosed mild AD and 9 controls. Their results demonstrated that PET imaging with the $\left[{ }^{11} \mathrm{C}\right.$ - $]$ PIB tracer provided quantitative information on amyloid deposits in living individuals with $A D$. Thanks to the favorable radiotracer profile, PIB has become the most commonly used PET amyloid agent, adopted in more than 40 research centers worldwide (Figure 5). However, a recent study highlighted that $\left[{ }^{11} \mathrm{C}\right.$-]PIB PET does not detect PrP-amyloid in prion disease patients, including variant Creutzfeldt-Jakob disease [167].

8.3. NIAD-4. Another emerging approach for in vivo detection of aggregated proteins is optical imaging through special near-infrared (NIR) fluorescent contrast agents. In 2005, following the rules reported in Table 1, Nesterov et al. designed a small molecule known as [ [ $5^{\prime}$-(4-hydroxyphenyl) [2,2' -bithiophen]-5-yl]methylene]-propanedinitrile, or simply NIAD-4 (Scheme 3) [133]. The binding studies with artificially aggregated amyloid protein assays revealed that NIAD4 binds to the same site as BTA- 1 with a $\mathrm{Ki}$ of $10 \mathrm{nM}$. This affinity is much higher than that of ThT $(\mathrm{Ki}=580 \mathrm{nM})$ and is close to that of high-affinity amyloid-binding compounds like PIB ( $\mathrm{Ki}=4.3 \mathrm{nM})$ [168]. Nesterov et al. [133] studied the specificity of NIAD- 4 binding to $\mathrm{A} \beta$ by in situ histochemical staining of fixed sections from transgenic mouse brain. Brain sections were obtained from aged APP transgenic mice with AD-like pathology. The brain sections were labeled with a NIAD-4 (10 $\mu \mathrm{M})$ solution in DMSO/propylene glycol for $15 \mathrm{~min}$ at room temperature. In vitro fluorescence imaging showed high-specificity labeling of NIAD-4, which revealed the exact position and size of the aggregated $\mathrm{A} \beta$ deposits. The authors [133] showed also the in vivo $\mathrm{A} \beta$ binding of NIAD-4 in aged APP transgenic mice. Mice were prepared with cranial windows to allow direct monitoring of the brain surface and then administered $10 \mu \mathrm{M}$ of $2 \mathrm{mg} / \mathrm{kg}$ NIAD- 4 solution by i.v. injection. Red fluorescence imaging using multiphoton microscopy showed that the agent readily crossed the BBB and labeled specifically both the plaques and cerebrovascular amyloid angiopathy. A radiolabeled version of NIAD-4 may also be advantageous for PET or SPECT imaging.

8.4. BF-168. Several stilbene derivatives have been synthesized as compounds for the probing of amyloid plaques [169]. Stilbene shows binding to $\mathrm{A} \beta$ aggregates in the nanomolar range [170]. Similar series of imaging probes were reported in [171], describing in vitro and in vivo properties of some styryl-based derivatives of ThT. The most promising one was 6-(2-fluoroethoxy)-2-[2-(4-methylaminophenyl)ethenyl]benzoxazole (BF-168) (Scheme 3). In AD brain sections, BF-168 selectively binds senile plaques and recognizes $\mathrm{A} \beta_{1-42}$-positive diffuse plaques as well as neuritic plaques. Intravenous injection of BF-168 in PS1/APP and APP23 transgenic mice resulted in specific in vivo labeling to both compact and diffuse amyloid deposits in the brain. In addition, ${ }^{18}$ F-radiolabeled BF-168 intravenously administered to normal mice showed abundant initial brain uptake (3.9\% ID/g at $2 \mathrm{~min}$ after injection, a sufficient level for brain imaging probe) and fast clearance $\left(t_{1 / 2}=24.7 \mathrm{~min}\right.$, indicating fast brain washout) sufficient for the compound to be a PET imaging probe. Furthermore, autoradiograms of brain sections from APP23 transgenic mice at $180 \mathrm{~min}$ after intravenous injection of $\left[{ }^{18} \mathrm{~F}\right] \mathrm{BF}-168$ showed selective labeling of brain amyloid deposits with little nonspecific binding. These findings strongly suggest that styrylbenzoxazole derivatives are promising candidate probes for PET and SPECT imaging for early detection of amyloid plaque formation in high-risk $\mathrm{AD}$ patients in presymptomatic stage [171]. Additionally, this new styrylbenzoxazole compound clearly labeled $\mathrm{PrP}^{\mathrm{Sc}}$ plaques in brain specimens from human 


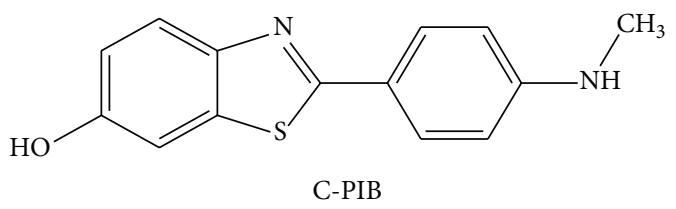

(a)

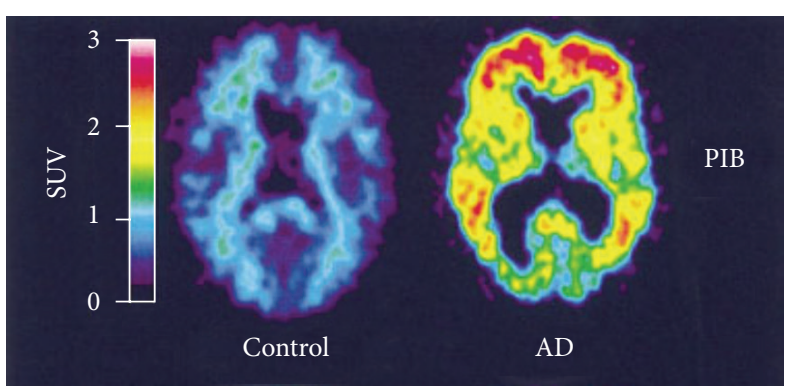

(b)

FIgURE 5: PET imaging of human AD brain using $\left[{ }^{11} \mathrm{C}-\right]$ PIB [12]. PIB standardized uptake value (SUV) images show a marked difference between PIB retention in AD patients and healthy control subjects. PET images of a 67-year-old healthy control subject (left) and a 79-year-old $\mathrm{AD}$ patient. The left column shows lack of PIB retention in the entire gray matter of the healthy subject.<smiles>N#CC(C#N)=Cc1ccc(-c2ccc(-c3ccc(O)cc3)s2)s1</smiles>

NIAD-4

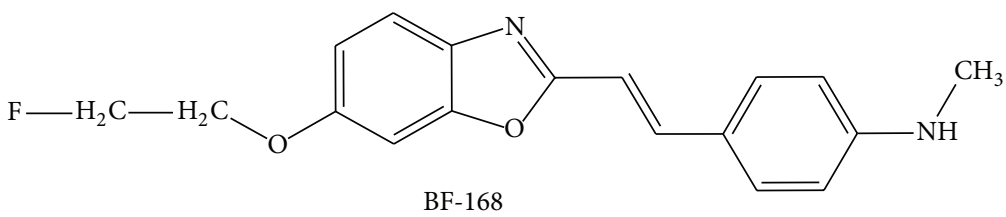

SCHEME 3: Chemical structures of potential in vivo imaging agents for $\beta$-amyloid plaques.

TSEs (sCJD and vCJD) [172]. BF-168 also inhibited abnormal PrP formation in TSE-infected cells with $\mathrm{IC}_{50}=0.4 \mathrm{nM}$ in ScN2a cell line model and prolonged the lives $(\sim 11.4 \%)$ of mice infected intracerebrally with TSE when the compound was administered intravenously at the preclinical stage. Even though their efficacy depends on the pathogen strain, these derivatives are a new class of compounds with potential as both therapeutic drugs and imaging probes for TSEs.

8.5. G8. Meanwhile, other styryl derivatives have been studied $[129,169,173,174]$. Li et al. [175] tested a group of styryl-based neutral compounds as potential in vivo imaging agents for $\beta$-amyloid plaques. The most promising one in this work was designed as STB-8 (Figure 6(a)), and its use in ex vivo and in vivo imaging experiments on an $\mathrm{AD}$ transgenic mouse model showed excellent $\mathrm{BBB}$ permeability and specific staining of the $\beta$-amyloid plaques (Figure 6(b)) [175].

A similar chemical scaffold was reported in our recent work [7]. The compound (E)-6-methyl-4-amino-2-styrylquinoline or G8 is a small molecule (Figure 6) with the proper features to potentially diagnose, deliver therapy, and monitor response to therapy in protein misfolding diseases. These features include compound fluorescent emission in the NIR region and the ability to interact with both $\mathrm{A} \beta$ and prion fibrils, staining them with high selectivity. Moreover, the compound possesses an antiaggregation property against $\mathrm{A} \beta_{1-42}$ using the well-known ThT-based fluorimetric assay [176] and prolongs the lag phase of $\operatorname{PrP}^{\mathrm{Sc}}$ formation in fibrillation assay [177]. At a concentration of $50 \mu \mathrm{M}, \mathrm{G} 8$ delayed fibril formation, extending the lag phase to $\geq 70 \mathrm{~h}$ (control: $59 \mathrm{~h}$ ). A similar profile was found for GN8, an antiprion drug candidate (Figure 6) for which a specific binding with $\operatorname{PrP}$ has been experimentally shown [178]. With such a good in vitro profile, we treated the ScGT1 and ScN2a cell lines with the compound, and the viability was quite good. At $1 \mu \mathrm{M}$ concentration, G8 showed a very low toxicity, with cell viability above $90 \%$ if compared with nontreated cells, while at a $10 \mu \mathrm{M}$ concentration it still showed a tolerable toxicity, with a residual $60 \%$ cell viability not different from that of drug candidate GN8. Starting from these nontoxic concentrations, we treated the cells to evaluate their inhibitory activity, and we found that the compound possessed a submicromolar capability to inhibit $\operatorname{PrP}^{\mathrm{Sc}}\left(\mathrm{EC}_{50}=0.5 \pm 0.1 \mu \mathrm{M}\right)$, greater than GN8 $\left(\mathrm{EC}_{50}=1.5 \pm 0.1 \mu \mathrm{M}\right)$ in our system. To confirm the labeling of $\operatorname{PrP}^{\mathrm{Sc}}$ aggregates in living cells, fluorescent staining with G8 was carried out using the same ScGT1 and ScN2a cell models. We found that $0.025 \%$ of $\mathrm{G} 8 \cdot \mathrm{HCl}$ $(0.84 \mathrm{mM})$ was sufficient to observe many fluorescent spots in the treated cells examined by fluorescent microscopy (Figure 6(c)). Importantly, no spots were observed in the 
<smiles>COc1ccc2nc(/C=C/c3ccc(-c4ccccc4)cc3)ccc2c1</smiles>

(a)

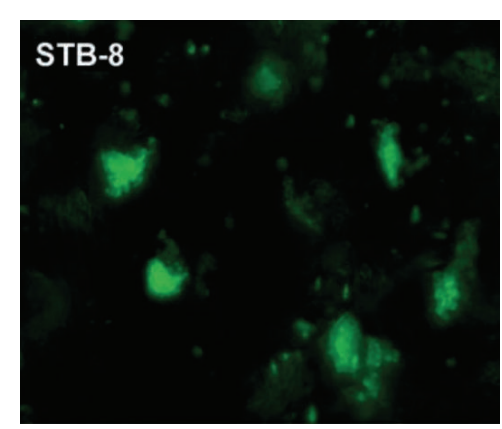

(b)

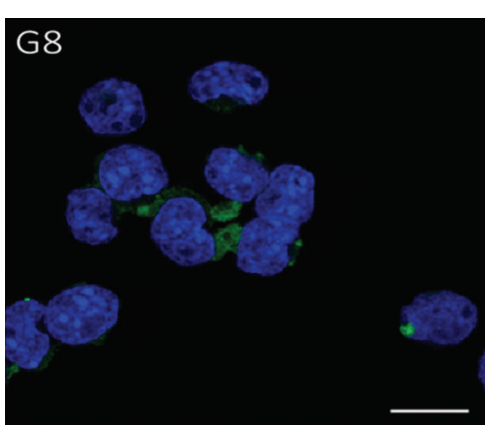

(c)

FIGURE 6: (a) Chemical formula of the three promising antiprionic compounds and in vitro staining with (b) STB-8 compound ( $\beta$-amyloid plaques) and (c) G8 compound ( $\mathrm{PrP}^{\mathrm{Sc}}$ deposits).

uninfected cells, confirming a specific binding. Furthermore, the staining pattern was consistent with that observed with $0.025 \%$ thioflavin S (ThS), a common $\operatorname{PrP}^{\mathrm{Sc}}$ dye. A further experiment proved that $\mathrm{G} 8 \cdot \mathrm{HCl}(0.25 \mathrm{mM})$ distinguishes the abnormal, aggregated, and $\mathrm{PK}$-resistant $\mathrm{PrP}^{\mathrm{Sc}}$ isoform from the normal, $\mathrm{PK}$-sensitive $\mathrm{PrP}^{\mathrm{C}}$ isoform. Thus, after eliminating $\operatorname{PrP}^{\mathrm{C}}$ through a $\mathrm{PK}$ digestion step, the previous fluorescence-staining pattern was observed. We primarily used the FITC filter set for these studies, but we confirmed the staining by employing the ThS one, which is within the NIR optical window. G8 was able to cross the BBB in an in vitro model, such as parallel artificial membrane permeability assay (PAMPA, Pe $23.1 \pm 1.910^{-6} \mathrm{~cm}^{-1}$ ).

From a medicinal chemistry perspective, G8 offers peculiar advantages: (1) a lower molecular weight than previous sensors [179] and (2) a small-molecule scaffold that is easily amenable to further manipulation to improve fluorescence response and amyloid-binding properties. Most importantly, with respect to the previously reported NIR amyloid sensors $[132,133,180-182]$ it offers the advantage of a concomitant promising antifibrillar profile (in vitro and in a cellular context), together with a low toxicity. If these distinctive properties are confirmed in vivo, G8 is likely to become the first purposely designed therapeutic and diagnostic (theranostic) tool for prion diseases and AD.

\section{Conclusion}

All the efforts made to date to develop rapid, accurate, and highly sensitive antemortem tests to detect prions early in the course of the disease have failed. Most tests still involve PK digestion, and the specificity and sensitivity of tests that do not use PK require further validation. Nevertheless, neuroimaging shows promise as a future clinical diagnostic tool for neurodegenerative diseases. Continued expansion of scientific imaging tools has been essential toward a new standard strategy that links established in vitro and cell culture experimental assays to imaging studies for living subjects. In fact, over the last few years the rapid development of different compounds suitable for visualizing aggregated $\beta$-sheet-rich proteins has led to the first promising in vivo studies of the amyloid ligands, such as PIB [12]. Florbetapir is the first radioactive dye for brain imaging of amyloid plaques to be approved by the FDA. With its introduction into the clinical practice, we are now effectively entering the era of neurodegenerative disease imaging.

Our hope is that our own G8 molecule [7] will confirm in vivo the results obtained in vitro. Molecular imaging in living subjects offers distinct advantages when compared with conventional in vitro and cell culture research techniques in biology. Therefore further work on promising imaging compounds is necessary to access in vivo studies. The use of these compounds could represent a good approach to detect 
and treat neurodegenerative disorders such as Alzheimer's disease and prion diseases. As the term theranostics is derived from the words therapeutics and diagnostics, the final application of theranostics is combining disease diagnosis and therapy. This combination in a single molecule enables real-time feedback on the biodistribution and the target site accumulation of the compound. The concurrent delivery and readout of efficacy can be exploited to tailor treatment regimens for specific treatment groups.

Effective treatments for devastating disorders such as Alzheimer's disease and prion diseases are urgently needed, as the world's population continues to age. We are confident that purposely-designed theranostics might soon become powerful tools to combat them.

\section{Acknowledgment}

The support of EU-COST Action TD1004 is acknowledged.

\section{References}

[1] C. C. Rowe, U. Ackerman, W. Browne et al., "Imaging of amyloid $\beta$ in Alzheimer's disease with 18F-BAY94-9172, a novel PET tracer: proof of mechanism," The Lancet Neurology, vol. 7, no. 2, pp. 129-135, 2008.

[2] G. J. O'keefe, T. H. Saunder, S. Ng et al., "Radiation dosimetry of beta-amyloid tracers 11c-Pib and 18f-bay94-9172," Journal of Nuclear Medicine, vol. 50, pp. 309-315.

[3] M. Koole, D. M. Lewis, C. Buckley et al., "Whole-body biodistribution and radiation dosimetry of 18F-GE067: a radioligand for in vivo brain amyloid imaging," Journal of Nuclear Medicine, vol. 50, no. 5, pp. 818-822, 2009.

[4] A. Fernandez-Fernandez, R. Manchanda, and A. J. McGoron, "Theranostic applications of nanomaterials in cancer: drug delivery, image-guided therapy, and multifunctional platforms," Applied Biochemistry and Biotechnology, vol. 165, no. 7-8, pp. 1628-1651, 2011.

[5] M. E. Lobatto, V. Fuster, Z. A. Fayad, and W. J. M. Mulder, "Perspectives and opportunities for nanomedicine in the management of atherosclerosis," Nature Reviews Drug Discovery, vol. 10, no. 11, pp. 835-852, 2011.

[6] P. Ramos-Cabrer, F. Campos, T. Sobrino, and J. Castillo, “Targeting the ischemic penumbra," Stroke, vol. 42, no. 1, pp. S7-S11, 2011.

[7] M. Staderini, S. Aulić, M. Bartolini et al., "A fluorescent styrylquinoline with combined therapeutic and diagnostic activities against Alzheimer's and Prion diseases," ACS Medicinal Chemistry Letters, vol. 4, pp. 225-229, 2013.

[8] S. B. Prusiner, "Molecular biology of prion diseases," Science, vol. 252, no. 5012, pp. 1515-1522, 1991.

[9] J. T. Jarrett and P. T. Lansbury Jr., "Seeding 'one-dimensional crystallization' of amyloid: a pathogenic mechanism in Alzheimer's disease and scrapie?" Cell, vol. 73, no. 6, pp. 1055-1058, 1993.

[10] G. S. Young, M. D. Geschwind, N. J. Fischbein et al., "Diffusionweighted and fluid-attenuated inversion recovery imaging in Creutzfeldt-Jakob disease: high sensitivity and specificity for diagnosis," American Journal of Neuroradiology, vol. 26, no. 6, pp. 1551-1562, 2005.

[11] X. Xiao, I. Cali, Z. Dong et al., "Protease-sensitive prions with 144-bp insertion mutations,” Aging, vol. 5, pp. 155-173, 2013.
[12] W. E. Klunk, H. Engler, A. Nordberg et al., "Imaging brain amyloid in Alzheimer's disease with pittsburgh compound-B," Annals of Neurology, vol. 55, no. 3, pp. 306-319, 2004.

[13] J. S. Griffith, "Nature of the scrapie agent: self-replication and scrapie," Nature, vol. 215, no. 5105, pp. 1043-1044, 1967.

[14] S. B. Prusiner, "Novel proteinaceous infectious particles cause scrapie," Science, vol. 216, no. 4542, pp. 136-144, 1982.

[15] H. G. Creutzfeldt, "Über eine eigenartige herdförmige erkrankung des zentralnervensystems," Zeitschrift für die Gesamte Neurologie und Psychiatrie, vol. 57, no. 1, pp. 1-18, 1920.

[16] A. Jakob, "Über eigenartige erkrankungen des zentralnervensystems mit bemerkenswertem anatomischen befunde (Spastische pseudosklerose-encephalomyclopathie mit disseminirrten degenerationsherden.)," Zeitschrift für die Gesamte Neurologie und Psychiatrie, vol. 64, no. 1, pp. 147-228, 1921.

[17] H. A. Kretzschmar, "Human prion diseases (spongiform encephalopathies)," Archives of Virology. Supplementum, vol. 7, pp. 261-293, 1993.

[18] J. Collinge, "Prion diseases of humans and animals: their causes and molecular basis," Annual Review of Neuroscience, vol. 24, pp. 519-550, 2001.

[19] J. Collinge, M. S. Palmer, and A. J. Dryden, "Genetic predisposition to iatrogenic Creutzfeldt-Jakob disease," The Lancet, vol. 337, no. 8755, pp. 1441-1442, 1991.

[20] M. S. Palmer, A. J. Dryden, J. T. Hughes, and J. Collinge, "Homozygous prion protein genotype predisposes to sporadic Creutzfeldt-Jakob disease," Nature, vol. 352, no. 6333, pp. 340342, 1991.

[21] H. S. Lee, N. Sambuughin, L. Cervenakova et al., "Ancestral origins and worldwide distribution of the PRNP 200K mutation causing familial Creutzfeldt-Jakob disease," The American Journal of Human Genetics, vol. 64, no. 4, pp. 1063-1070, 1999.

[22] J. M. Bertoni, P. Brown, L. G. Goldfarb, R. Rubenstein, and D. C. Gajdusek, "Familial Creutzfeldt-Jakob disease (codon 200 mutation) with supranuclear palsy," Journal of the American Medical Association, vol. 268, no. 17, pp. 2413-2415, 1992.

[23] L. G. Goldfarb, E. Mitrova, P. Brown, B. H. Toh, and D. C. Gajdusek, "Mutation of codon 200 of scrapie amyloid protein gene in two clusters of Creutzfeldt-Jakob disease in Slovakia," The Lancet, vol. 336, no. 8713, pp. 514-515, 1990.

[24] D. Goldgaber, L. G. Goldfarb, P. Brown et al., "Mutations in familial Creutzfeldt-Jakob disease and Gerstmann-StrausslerScheinker's syndrome," Experimental Neurology, vol. 106, no. 2, pp. 204-206, 1989.

[25] L. G. Goldfarb, P. Brown, M. Haltia et al., "Creutzfeldt-Jakob disease cosegregates with the codon 178Asn PRNP mutation in families of European origin," Annals of Neurology, vol. 31, no. 3, pp. 274-281, 1992.

[26] M. Haltia, J. Kovanen, L. G. Goldfarb, P. Brown, and D. C. Gajdusek, "Familial Creutzfeldt-Jakob disease in Finland: epidemiological, clinical, pathological and molecular genetic studies," European Journal of Epidemiology, vol. 7, no. 5, pp. 494$500,1991$.

[27] A. Nieto, L. G. Goldfarb, P. Brown et al., "Codon 178 mutation in ethnically diverse Creutzfeldt-Jakob disease families," The Lancet, vol. 337, no. 8741, pp. 622-623, 1991.

[28] J. A. Mastrianni, S. Capellari, G. C. Telling et al., "Inherited prion disease caused by the V210I mutation: transmission to transgenic mice," Neurology, vol. 57, no. 12, pp. 2198-2205, 2001.

[29] P. Duffy, J. Wolf, G. Collins, A. G. DeVoe, B. Streeten, and D. Cowen, "Letter: possible person-to-person transmission 
of Creutzfeldt-Jakob disease," The New England Journal of Medicine, vol. 290, no. 12, pp. 692-693, 1974.

[30] P. Brown, J. P. Brandel, T. Sato et al., "Iatrogenic CreutzfeldtJakob disease, final assessment," Emerging Infectious Diseases, vol. 18, pp. 901-907, 2012.

[31] R. G. Will, J. W. Ironside, M. Zeidler et al., "A new variant of Creutzfeldt-Jakob disease in the UK," The Lancet, vol. 347, no. 9006, pp. 921-925, 1996.

[32] S. N. Cousens, E. Vynnycky, M. Zeidier, R. G. Will, and P. G. Smith, "Predicting the CDJ epidemic in humans," Nature, vol. 385, no. 6613, pp. 197-198, 1997.

[33] A. C. Ghani, N. M. Ferguson, C. A. Donnelly, T. J. Hagenaars, and R. M. Anderson, "Epidemiological determinants of the pattern and magnitude of the vCJD epidemic in Great Britain," Proceedings of the Royal Society B, vol. 265, no. 1413, pp. 24432452, 1998.

[34] M. R. Scott, R. Will, J. Ironside et al., "Compelling transgenetic evidence for transmission of bovine spongiform encephalopathy prions to humans," Proceedings of the National Academy of Sciences of the United States of America, vol. 96, no. 26, pp. 15137$15142,1999$.

[35] R. G. Will, “The transmission of prions to humans," Acta Paediatrica, vol. 88, no. 433, pp. 28-32, 1999.

[36] J. Collinge, "New diagnostic tests for prion diseases," The New England Journal of Medicine, vol. 335, no. 13, pp. 963-965, 1996.

[37] J. Collinge, K. C. L. Sidle, J. Meads, J. Ironside, and A. F. Hill, "Molecular analysis of prion strain variation and the aetiology of 'new variant' CJD," Nature, vol. 383, no. 6602, pp. 685-690, 1996.

[38] A. H. Peden, M. W. Head, D. L. Ritchie, P. J. E. Bell, and P. J. W. Ironside, "Preclinical vCJD after blood transfusion in a PRNP codon 129 heterozygous patient," The Lancet, vol. 364, no. 9433, pp. 527-529, 2004.

[39] L. Cervenáková, L. G. Goldfarb, R. Garruto, H.-S. Lee, D. C. Gajdusek, and P. Brown, "Phenotype-genotype studies in kuru: implications for new variant Creutzfeldt-Jakob disease," Proceedings of the National Academy of Sciences of the United States of America, vol. 95, no. 22, pp. 13239-13241, 1998.

[40] O. Windl, M. Dempster, J. P. Estibeiro et al., "Genetic basis of Creutzfeldt-Jakob disease in the United Kingdom: a systematic analysis of predisposing mutations and allelic variation in the PRNP gene," Human Genetics, vol. 98, no. 3, pp. 259-264, 1996.

[41] H. F. Baker, M. Poulter, T. J. Cros et al., "Aminoacid polymorphism in human prion protein and age at death in inherited prion disease," The Lancet, vol. 337, no. 8752, p. 1286, 1991.

[42] K. Hsiao, S. R. Dlouhy, M. R. Farlow et al., "Mutant prion proteins in Gerstmann-Sträussler-Scheinker disease with neurofibrillary tangles," Nature Genetics, vol. 1, no. 1, pp. 68-71, 1992.

[43] B. Ghetti, S. R. Dlouhy, G. Giaccone et al., "Gerstmann-Straussler-Scheinker disease and the Indiana kindred," Brain Pathology, vol. 5, pp. 61-75, 1995.

[44] C. L. Masters, D. C. Gajdusek, and C. J. Gibbs Jr., "CreutzfeldtJakob disease virus isolations from the Gerstmann-Straussler syndrome with an analysis of the various forms of amyloid plaque deposition in the virus-induced spongiform encephalopathies," Brain, vol. 104, pp. 559-588, 1981.

[45] J. Gerstmann, E. Sträussler, and I. Scheinker, "Über eine eigenartige hereditär-familiäre Erkrankung des Zentralnervensystems. Zugleich ein Beitrag zur Frage des vorzeitigen lokalen Alterns," Zeitschrift für die Gesamte Neurologie und Psychiatrie, vol. 154, pp. 736-762, 1936.
[46] K. Hsiao, H. F. Baker, T. J. Crow et al., "Linkage of a prion protein missense variant to Gerstmann-Straussler syndrome," Nature, vol. 338, no. 6213, pp. 342-345, 1989.

[47] M. Yamada, Y. Itoh, H. Fujigasaki et al., "A missense mutation at codon 105 with codon 129 polymorphism of the prion protein gene in a new variant of Gerstmann-Straussler-Scheinker disease," Neurology, vol. 43, no. 12 I, pp. 2723-2724, 1993.

[48] K. Doh-ura, J. Tateishi, H. Sasaki, T. Kitamoto, and Y. Sakaki, "Pro $\rightarrow$ Leu change at position 102 of prion protein is the most common but not the sole mutation related to GerstmannStraussler syndrome," Biochemical and Biophysical Research Communications, vol. 163, no. 2, pp. 974-979, 1989.

[49] P. K. Panegyres, K. Toufexis, B. A. Kakulas et al., "A new PRNP mutation (G131V) associated with Gerstmann-Sträussler-Scheinker disease," Archives of Neurology, vol. 58, no. 11, pp. 1899-1902, 2001.

[50] S. R. Dlouhy, K. Hsiao, M. R. Farlow et al., "Linkage of the Indiana kindred of Gerstmann-Sträussler-Scheinker disease to the prion protein gene," Nature Genetics, vol. 1, no. 1, pp. 64-67, 1992.

[51] J. J. Helmus, K. Surewicz, P. S. Nadaud, W. K. Surewicz, and C. P. Jaroniec, "Molecular conformation and dynamics of the Y145Stop variant of human prion protein in amyloid fibrils," Proceedings of the National Academy of Sciences of the United States of America, vol. 105, no. 17, pp. 6284-6289, 2008.

[52] J. J. Helmus, K. Surewicz, W. K. Surewicz, and C. P. Jaroniec, "Conformational flexibility of Y145stop human prion protein amyloid fibrils probed by solid-state nuclear magnetic resonance spectroscopy," Journal of the American Chemical Society, vol. 132, no. 7, pp. 2393-2403, 2010.

[53] C. Jansen, P. Parchi, S. Capellari et al., "Prion protein amyloidosis with divergent phenotype associated with two novel nonsense mutations in PRNP," Acta Neuropathologica, vol. 119, no. 2, pp. 189-197, 2010.

[54] G. G. Kovács, G. Trabattoni, J. A. Hainfellner, J. W. Ironside, R. S. G. Knight, and H. Budka, "Mutations of the prion protein gene: phenotypic spectrum," Journal of Neurology, vol. 249, no. 11, pp. 1567-1582, 2002.

[55] C. Jansen, W. Voet, M. W. Head et al., "A novel seven-octapeptide repeat insertion in the prion protein gene (PRNP) in a Dutch pedigree with Gerstmann-Sträussler-Scheinker disease phenotype: comparison with similar cases from the literature," Acta Neuropathologica, vol. 121, no. 1, pp. 59-68, 2011.

[56] E. Lugaresi, R. Medori, and P. Montagna, "Fatal familial insomnia and dysautonomia with selective degeneration of thalamic nuclei," The New England Journal of Medicine, vol. 315, no. 16, pp. 997-1003, 1986.

[57] G. Almer, J. A. Hainfellner, T. Brücke et al., "Fatal familial insomnia: a new Austrian family," Brain, vol. 122, no. 1, pp. 516, 1999.

[58] A. Carota, G. P. Pizzolato, P. Gailloud et al., "A panencephalopathic type of Creutzfeldt-Jakob disease with selective lesions of the thalamic nuclei in 2 Swiss patients," Clinical Neuropathology, vol. 15, no. 3, pp. 125-134, 1996.

[59] A. Padovani, M. D’Alessandro, P. Parchi et al., "Fatal familial insomnia in a new Italian kindred," Neurology, vol. 51, no. 5, pp. 1491-1494, 1998.

[60] C. A. McLean, E. Storey, R. J. M. Gardner, A. E. G. Tannenberg, L. Cervenáková, and P. Brown, “The D178N (cis-129M) 'fatal familial insomnia' mutation associated with diverse clinicopathologic phenotypes in an Australian kindred," Neurology, vol. 49, no. 2, pp. 552-558, 1997. 
[61] M. Nagayama, Y. Shinohara, H. Furukawa, and T. Kitamoto, "Fatal familial insomnia with a mutation at codon 178 of the priori protein gene: first report from Japan," Neurology, vol. 47, no. 5, pp. 1313-1316, 1996.

[62] R. Medori, H.-J. Tritschler, A. LeBlanc et al., "Fatal familial insomnia, a prion disease with a mutation at codon 178 of the prion protein gene," The New England Journal of Medicine, vol. 326, no. 7, pp. 444-449, 1992.

[63] J. A. Mastrianni, R. Nixon, R. Layzer et al., "Prion protein conformation in a patient with sporadic fatal insomnia," The New England Journal of Medicine, vol. 340, no. 21, pp. 1630-1638, 1999.

[64] F. Scaravilli, R. J. Cordery, H. Kretzschmar et al., "Sporadic fatal insomnia: a case study," Annals of Neurology, vol. 48, pp. 665668, 2000.

[65] P. Parchi, S. Capellari, S. Chin et al., "A subtype of sporadic prion disease mimicking fatal familial insomnia," Neurology, vol. 52, no. 9, pp. 1757-1763, 1999.

[66] P. Montagna, P. Gambetti, P. Cortelli, and E. Lugaresi, "Familial and sporadic fatal insomnia," The Lancet Neurology, vol. 2, no. 3, pp. 167-176, 2003.

[67] D. C. Gajdusek and V. Zigas, "Degenerative disease of the central nervous system in New Guinea, the endemic occurrence of kuru in the native population," The New England Journal of Medicine, vol. 257, no. 20, pp. 974-978, 1957.

[68] L. Westergard, H. M. Christensen, and D. A. Harris, "The cellular prion protein (PrPC): its physiological function and role in disease," Biochimica et Biophysica Acta, vol. 1772, no. 6, pp. 629-644, 2007.

[69] K. E. Nazor, T. Seward, and G. C. Telling, "Motor behavioral and neuropathological deficits in mice deficient for normal prion protein expression," Biochimica et Biophysica Acta, vol. 1772, no. 6, pp. 645-653, 2007.

[70] H. Bueler, M. Fischer, Y. Lang et al., "Normal development and behaviour of mice lacking the neuronal cell-surface $\operatorname{PrP}$ protein," Nature, vol. 356, no. 6370, pp. 577-582, 1992.

[71] J. C. Manson, A. R. Clarke, M. L. Hooper, L. Aitchison, I. McConnell, and J. Hope, "129/Ola mice carrying a null mutation in PrP that abolishes mRNA production are developmentally normal," Molecular Neurobiology, vol. 8, no. 2-3, pp. 121-127, 1994.

[72] H. Bueler, A. Aguzzi, A. Sailer et al., "Mice devoid of PrP are resistant to scrapie," Cell, vol. 73, no. 7, pp. 1339-1347, 1993.

[73] J.-G. Fournier, F. Escaig-Haye, T. B. de Villemeur, and O. Robain, "Ultrastructural localization of cellular prion protein (PrPc) in synaptic boutons of normal hamster hippocampus," Comptes Rendus de l'Academie des Sciences, vol. 318, no. 3, pp. 339-344, 1995.

[74] K. L. Moya, N. Sales, R. Hassig et al., "Immunolocalization of the cellular prion protein in normal brain," Microscopy Research and Technique, vol. 50, pp. 58-65, 2000.

[75] N. Salès, K. Rodolfo, R. Hässig, B. Faucheux, L. Di Giamberardino, and K. L. Moya, "Cellular prion protein localization in rodent and primate brain," European Journal of Neuroscience, vol. 10, no. 7, pp. 2464-2471, 1998.

[76] P. Sanchez-Juan, A. Green, A. Ladogana et al., "CSF tests in the differential diagnosis of Creutzfeldt-Jakob disease," Neurology, vol. 67, no. 4, pp. 637-643, 2006.

[77] I. Zerr, K. Kallenberg, D. M. Summers et al., "Updated clinical diagnostic criteria for sporadic Creutzfeldt-Jakob disease," Brain, vol. 132, no. 4, pp. 2659-2668, 2009.
[78] M. Zeidler, G. E. Stewart, C. R. Barraclough et al., "New variant Creutzfeldt-Jakob disease: neurological features and diagnostic tests," The Lancet, vol. 350, no. 9082, pp. 903-907, 1997.

[79] R. T. Johnson and C. J. Gibbs Jr., "Creutzfeldt-Jakob disease and related transmissible spongiform encephalopathies," The New England Journal of Medicine, vol. 339, no. 27, pp. 1994-2004, 1998.

[80] K. K. Hsiao, D. Groth, M. Scott et al., "Serial transmission in rodents of neurodegeneration from transgenic mice expressing mutant prion protein," Proceedings of the National Academy of Sciences of the United States of America, vol. 91, no. 19, pp. 91269130, 1994.

[81] G. C. Telling, M. Scott, K. K. Hsiao et al., "Transmission of Creutzfeldt-Jakob disease from humans to transgenic mice expressing chimeric human-mouse prion protein," Proceedings of the National Academy of Sciences of the United States of America, vol. 91, no. 21, pp. 9936-9940, 1994.

[82] J. Safar, H. Wille, V. Itri et al., "Eight prion strains have $\operatorname{PrP}(\mathrm{Sc})$ molecules with different conformations," Nature Medicine, vol. 4, no. 10, pp. 1157-1165, 1998.

[83] P. Gambetti, Z. Dong, J. Yuan et al., "A novel human disease with abnormal prion protein sensitive to protease," Annals of Neurology, vol. 63, no. 6, pp. 697-708, 2008.

[84] D. W. Colby, R. Wain, I. V. Baskakov et al., "Protease-sensitive synthetic prions," PLoS Pathogens, vol. 6, no. 1, Article ID e1000736, 2010.

[85] J. G. Safar, M. Scott, J. Monaghan et al., "Measuring prions causing bovine spongiform encephalopathy or chronic wasting disease by immunoassays and transgenic mice," Nature Biotechnology, vol. 20, no. 11, pp. 1147-1150, 2002.

[86] I. S. Lee, J. R. Long, S. B. Prusiner, and J. G. Safar, "Selective precipitation of prions by polyoxometalate complexes," Journal of the American Chemical Society, vol. 127, no. 40, pp. $13802-$ 13803, 2005.

[87] G. P. Saborio, B. Permanne, and C. Soto, "Sensitive detection of pathological prion protein by cyclic amplification of protein misfolding," Nature, vol. 411, no. 6839, pp. 810-813, 2001.

[88] P. Saá, J. Castilla, and C. Soto, "Ultra-efficient replication of infectious prions by automated protein misfolding cyclic amplification," The Journal of Biological Chemistry, vol. 281, no. 46, pp. 35245-35252, 2006.

[89] K. C. Gough, C. A. Baker, H. C. Rees et al., "The oral secretion of infectious scrapie prions occurs in preclinical sheep with a range of PRNP genotypes," Journal of Virology, vol. 86, no. 1, pp. 566-571, 2012.

[90] L. A. Terry, L. Howells, K. Bishop et al., "Detection of prions in the faeces of sheep naturally infected with classical scrapie," Veterinary Research, vol. 42, no. 1, article 65, 2011.

[91] B. C. Maddison, H. C. Raes, C. A. Baker et al., "Prions are secreted into the oral cavity in sheep with preclinical scrapie," Journal of Infectious Diseases, vol. 201, no. 11, pp. 1672-1676, 2010.

[92] B. C. Maddison, C. A. Baker, H. C. Rees et al., "Prions are secreted in milk from clinically normal scrapie-exposed sheep," Journal of Virology, vol. 83, no. 16, pp. 8293-8296, 2009.

[93] L. Thorne and L. A. Terry, "In vitro amplification of PrPSc derived from the brain and blood of sheep infected with scrapie," Journal of General Virology, vol. 89, no. 12, pp. 3177-3184, 2008.

[94] G. Legname, I. V. Baskakov, H.-O. B. Nguyen et al., "Synthetic mammalian prions," Science, vol. 305 , no. 5684, pp. 673-676, 2004 . 
[95] D. W. Colby, Q. Zhang, S. Wang et al., "Prion detection by an amyloid seeding assay," Proceedings of the National Academy of Sciences of the United States of America, vol. 104, no. 52, pp. 20914-20919, 2007.

[96] C. D. Orrú, J. M. Wilham, L. D. Raymond et al., "Prion disease blood test using immunoprecipitation and improved quakinginduced conversion," mBio, vol. 2, no. 3, pp. e00078-e00011, 2011.

[97] R. Atarashi, J. M. Wilham, L. Christensen et al., "Simplified ultrasensitive prion detection by recombinant $\operatorname{PrP}$ conversion with shaking," Nature Methods, vol. 5, no. 3, pp. 211-212, 2008.

[98] C. D. Orrú, J. M. Wilham, A. G. Hughson et al., "Human variant Creutzfeldt-Jakob disease and sheep scrapie PrPres detection using seeded conversion of recombinant prion protein," Protein Engineering, Design and Selection, vol. 22, no. 8, pp. 515-521, 2009.

[99] R. Atarashi, K. Satoh, K. Sano et al., "Ultrasensitive human prion detection in cerebrospinal fluid by real-time quaking-induced conversion," Nature Medicine, vol. 17, no. 2, pp. 175-178, 2011.

[100] J. M. Wilham, C. D. Orrú, R. A. Bessen et al., "Rapid end-point quantitation of prion seeding activity with sensitivity comparable to bioassays," PLoS Pathogens, vol. 6, no. 12, Article ID e1001217, 2010.

[101] K. Gmitterová, U. Heinemann, M. Bodemer et al., "14-3-3 CSF levels in sporadic Creutzfeldt-Jakob disease differ across molecular subtypes," Neurobiology of Aging, vol. 30, no. 11, pp. 1842-1850, 2009.

[102] S. Haik, J. P. Brandel, D. Salomon et al., "Compassionate use of quinacrine in Creutzfeldt-Jakob disease fails to show significant effects," Neurology, vol. 63, no. 12, pp. 2413-2415, 2004.

[103] I. R. Whittle, R. S. G. Knight, and R. G. Will, "Unsuccessful intraventricular pentosan polysulphate treatment of variant Creutzfeldt-Jakob disease," Acta Neurochirurgica, vol. 148, no. 6, pp. 677-678, 2006.

[104] I. H. Gilbert and H. Rudyk, "Inhibitors of protease-resistant prion formation," International Antiviral News, vol. 7, no. 5, pp. 78-82, 1999.

[105] T. Koster, K. Singh, M. Zimmermann, and E. Gruys, "Emerging therapeutic agents for transmissible spongiform encephalopathies: a review," Journal of Veterinary Pharmacology and Therapeutics, vol. 26, no. 5, pp. 315-326, 2003.

[106] J. Pankiewicz, F. Prelli, M.-S. Sy et al., "Clearance and prevention of prion infection in cell culture by anti-PrP antibodies," European Journal of Neuroscience, vol. 23, no. 10, pp. 2635-2647, 2006.

[107] S. Supattapone, K. Nishina, and J. R. Rees, "Pharmacological approaches to prion research," Biochemical Pharmacology, vol. 63, no. 8, pp. 1383-1388, 2002.

[108] C. Farquhar, A. Dickinson, and M. Bruce, "Prophylactic potential of pentosan polysulphate in transmissible spongiform encephalopathies," The Lancet, vol. 353, no. 9147, p. 117, 1999.

[109] B. Caughey, D. Ernst, and R. E. Race, "Congo red inhibition of scrapie agent replication," Journal of Virology, vol. 67, no. 10, pp. 6270-6272, 1993.

[110] R. Demaimay, K. T. Adjou, V. Beringue et al., "Late treatment with polyene antibiotics can prolong the survival time of scrapie-infected animals," Journal of Virology, vol. 71, no. 12, pp. 96859689, 1997.

[111] F. Tagliavini, R. A. McArthur, B. Canciani et al., "Effectiveness of anthracycline against experimental prion disease in Syrian hamsters," Science, vol. 276, no. 5315, pp. 1119-1122, 1997.
[112] W. S. Caughey, L. D. Raymond, M. Horiuchi, and B. Caughey, "Inhibition of protease-resistant prion protein formation by porphyrins and phthalocyanines," Proceedings of the National Academy of Sciences of the United States of America, vol. 95, no. 21, pp. 12117-12122, 1998.

[113] S. Bach, N. Talarek, T. Andrieu et al., "Isolation of drugs active against mammalian prions using a yeast-based screening assay," Nature Biotechnology, vol. 21, no. 9, pp. 1075-1081, 2003.

[114] W. E. G. Müller, J.-L. Laplanche, H. Ushijima, and H. C. Schröder, "Novel approaches in diagnosis and therapy of Creutzfeldt-Jakob disease," Mechanisms of Ageing and Development, vol. 116, no. 2-3, pp. 193-218, 2000.

[115] K. Doh-Ura, T. Iwaki, and B. Caughey, "Lysosomotropic agents and cysteine protease inhibitors inhibit scrapie- associated prion protein accumulation," Journal of Virology, vol. 74, no. 10, pp. 4894-4897, 2000.

[116] C. Korth, B. C. H. May, F. E. Cohen, and S. B. Prusiner, "Acridine and phenothiazine derivatives as pharmacotherapeutics for prion disease," Proceedings of the National Academy of Sciences of the United States of America, vol. 98, no. 17, pp. 9836-9841, 2001.

[117] B. C. H. May, A. T. Fafarman, S. B. Hong et al., "Potent inhibition of scrapie prion replication in cultured cells by bis-acridines," Proceedings of the National Academy of Sciences of the United States of America, vol. 100, no. 6, pp. 3416-3421, 2003.

[118] F. Goñi, E. Knudsen, F. Schreiber et al., "Mucosal vaccination delays or prevents prion infection via an oral route," Neuroscience, vol. 133, no. 2, pp. 413-421, 2005.

[119] E. M. Sigurdsson and T. Wisniewski, "Promising developments in prion immunotherapy," Expert Review of Vaccines, vol. 4, no. 5, pp. 607-610, 2005.

[120] U. Bertsch, K. F. Winklhofer, T. Hirschberger et al., "Systematic identification of antiprion drugs by high-throughput screening based on scanning for intensely fluorescent targets," Journal of Virology, vol. 79, no. 12, pp. 7785-7791, 2005.

[121] D. A. Kocisko, G. S. Baron, R. Rubenstein, J. Chen, S. Kuizon, and B. Caughey, "New inhibitors of scrapie-associated prion protein formation in a library of 2,000 drugs and natural products," Journal of Virology, vol. 77, no. 19, pp. 10288-10294, 2003.

[122] E. D. Agdeppa, V. Kepe, J. Liu et al., "Binding characteristics of radiofluorinated 6-dialkylamino-2-naphthylethylidene derivatives as positron emission tomography imaging probes for beta-amyloid plaques in Alzheimer's disease," Journal of Neuroscience, vol. 21, no. 24, p. RC189, 2001.

[123] Z.-P. Zhuang, M.-P. Kung, A. Wilson et al., "Structure-activity relationship of imidazo[1,2-a]pyridines as ligands for detecting $\beta$-amyloid plaques in the brain," Journal of Medicinal Chemistry, vol. 46, no. 2, pp. 237-243, 2003.

[124] M. Bresjanac, L. M. Smid, T. D. Vovko, A. Petrič, J. R. Barrio, and M. Popovic, "Molecular-imaging probe 2-(1-6-[(2-fluoroethyl)(methyl) amino]-2-naphthylethylidene) malononitrile labels prion plaques in vitro," Journal of Neuroscience, vol. 23, no. 22, pp. 8029-8033, 2003.

[125] B. J. Bacskai, W. E. Klunk, C. A. Mathis, and B. T. Hyman, "Imaging amyloid- $\beta$ deposits in vivo," Journal of Cerebral Blood Flow and Metabolism, vol. 22, no. 9, pp. 1035-1041, 2002.

[126] J. F. Poduslo, T. M. Wengenack, G. L. Curran et al., "Molecular targeting of Alzheimer's amyloid plaques for contrast-enhanced magnetic resonance imaging," Neurobiology of Disease, vol. 11, no. 2, pp. 315-329, 2002. 
[127] M. Higuchi, N. Iwata, Y. Matsuba, K. Sato, K. Sasamoto, and T. C. Saido, "19F and 1 H MRI detection of amyloid $\beta$ plaques in vivo," Nature Neuroscience, vol. 8, no. 4, pp. 527-533, 2005.

[128] K. Shoghi-Jadid, G. W. Small, E. D. Agdeppa et al., "Localization of neurofibrillary tangles and beta-amyloid plaques in the brains of living patients with Alzheimer disease," American Journal of Geriatric Psychiatry, vol. 10, no. 1, pp. 24-35, 2002.

[129] M. Ono, A. Wilson, J. Nobrega et al., "11C-labeled stilbene derivatives as $\mathrm{A} \beta$-aggregate-specific PET imaging agents for Alzheimer's disease," Nuclear Medicine and Biology, vol. 30, no. 6, pp. 565-571, 2003.

[130] H. Engler, A. Forsberg, O. Almkvist et al., "Two-year followup of amyloid deposition in patients with Alzheimer's disease," Brain, vol. 129, no. 11, pp. 2856-2866, 2006.

[131] C. C. Rowe, S. Ng, U. Ackermann et al., "Imaging $\beta$-amyloid burden in aging and dementia," Neurology, vol. 68, no. 20, pp. 1718-1725, 2007.

[132] M. Hintersteiner, A. Enz, P. Frey et al., "In vivo detection of amyloid- $\beta$ deposits by near-infrared imaging using an oxazinederivative probe," Nature Biotechnology, vol. 23, no. 5, pp. 577583,2005

[133] E. E. Nesterov, J. Skoch, B. T. Hyman, W. E. Klunk, B. J. Bacskai, and T. M. Swager, "In vivo optical imaging of amyloid aggregates in brain: design of fluorescent markers," Angewandte Chemie, vol. 44, no. 34, pp. 5452-5456, 2005.

[134] S. R. Choi, G. Golding, Z. Zhuang et al., "Preclinical properties of18F-AV-45: a PET agent for A $\beta$ plaques in the brain," Journal of Nuclear Medicine, vol. 50, no. 11, pp. 1887-1894, 2009.

[135] D. F. Wong, P. B. Rosenberg, Y. Zhou et al., "In vivo imaging of amyloid deposition in Alzheimer disease using the radioligand18F-AV-45 (flobetapir F 18)," Journal of Nuclear Medicine, vol. 51, no. 6, pp. 913-920, 2010.

[136] G. T. Westermark, K. H. Johnson, and P. Westermark, "Staining methods for identification of amyloid in tissue," Methods in Enzymology, vol. 309, pp. 3-25, 1999.

[137] D. P. Steensma, ““Congo” red: out of Africa?” Archives of Pathology and Laboratory Medicine, vol. 125, no. 2, pp. 250-252, 2001.

[138] W. E. Klunk, J. W. Pettegrew, and D. J. Abraham, "Quantitative evaluation of Congo red binding to amyloid-like proteins with a beta-pleated sheet conformation," Journal of Histochemistry and Cytochemistry, vol. 37, no. 8, pp. 1273-1281, 1989.

[139] W. E. Klunk, M. L. Debnath, and J. W. Pettegrew, "Development of small molecule probes for the beta-amyloid protein of Alzheimer's disease," Neurobiology of Aging, vol. 15, no. 6, pp. 691698, 1994.

[140] J. H. Cooper, "Selective amyloid staining as a function of amyloid composition and structure. Histochemical analysis of the alkaline Congo red, standardized toluidine blue, and iodine methods," Laboratory Investigation, vol. 31, no. 3, pp. 232-238, 1974.

[141] P. Frid, S. V. Anisimov, and N. Popovic, "Congo red and protein aggregation in neurodegenerative diseases," Brain Research Reviews, vol. 53, no. 1, pp. 135-160, 2007.

[142] M.-C. Burgevin, M. Passat, N. Daniel, M. Capet, and A. Doble, "Congo red protects against toxicity of $\beta$-amyloid peptides on rat hippocampal neurones," NeuroReport, vol. 5, no. 18, pp. 2429-2432, 1994.

[143] A. Lorenzo and B. A. Yankner, " $\beta$-Amyloid neurotoxicity requires fibril formation and is inhibited by Congo red," Proceedings of the National Academy of Sciences of the United States of America, vol. 91, no. 25, pp. 12243-12247, 1994.
[144] S. J. Pollack, "Sulfonated dyes attenuate the toxic effects of $\beta$ amyloid in a structure-specific fashion," Neuroscience Letters, vol. 197, no. 3, pp. 211-214, 1995.

[145] G. P. Gellermann, K. Ullrich, A. Tannert et al., "Alzheimer-like plaque formation by human macrophages is reduced by fibrillation inhibitors and lovastatin," Journal of Molecular Biology, vol. 360, no. 2, pp. 251-257, 2006.

[146] D. C. Crowther, K. J. Kinghorn, E. Miranda et al., "Intraneuronal $\mathrm{A} \beta$, non-amyloid aggregates and neurodegeneration in a Drosophila model of Alzheimer's disease," Neuroscience, vol. 132, no. 1, pp. 123-135, 2005.

[147] B. Caughey and R. E. Race, "Potent inhibition of scrapie-associated PrP accumulation by Congo red," Journal of Neurochemistry, vol. 59, no. 2, pp. 768-771, 1992.

[148] L. Ingrosso, A. Ladogana, and M. Pocchiari, "Congo red prolongs the incubation period in scrapie-infected hamsters," Journal of Virology, vol. 69, no. 1, pp. 506-508, 1995.

[149] G. Poli, W. Ponti, G. Carcassola et al., "In vitro evaluation of the anti-prionic activity of newly synthesized Congo red derivatives," Arzneimittel-Forschung, vol. 53, no. 12, pp. 875-888, 2003.

[150] P. E. Fraser, J. T. Nguyen, D. T. Chin, and D. A. Kirschner, "Effects of sulfate ions on Alzheimer $\beta / \mathrm{A} 4$ peptide assemblies: implications for amyloid fibril-proteoglycan interactions," Journal of Neurochemistry, vol. 59, no. 4, pp. 1531-1540, 1992.

[151] H. Rudyk, S. Vasiljevic, R. M. Hennion, C. R. Birkett, J. Hope, and I. H. Gilbert, "Screening Congo red and its analogues for their ability to prevent the formation of PrP-res in scrapieinfected cells," Journal of General Virology, vol. 81, no. 4, pp. 1155-1164, 2000.

[152] W. E. Klunk, M. L. Debnath, and J. W. Pettegrew, "ChrysamineG binding to Alzheimer and control brain: autopsy study of a new amyloid probe," Neurobiology of Aging, vol. 16, no. 4, pp. 541-548, 1995.

[153] W. E. Klunk, M. L. Debnath, A. M. C. Koros, and J. W. Pettegrew, "Chrysamine-G, a lipophilic analogue of Congo red, inhibits A $\beta$-induced toxicity in PC12 cells," Life Sciences, vol. 63, no. 20, pp. 1807-1814, 1998.

[154] S. D. Styren, R. L. Hamilton, G. C. Styren, and W. E. Klunk, "X34, a fluorescent derivative of Congo red: a novel histochemical stain for Alzheimer's disease pathology," Journal of Histochemistry and Cytochemistry, vol. 48, no. 9, pp. 1223-1232, 2000.

[155] D. M. Skovronsky, B. Zhang, M.-P. Kung, H. F. Kung, J. Q. Trojanowski, and V. M.-Y. Lee, "In vivo detection of amyloid plaques in a mouse model of Alzheimer's disease," Proceedings of the National Academy of Sciences of the United States of America, vol. 97, no. 13, pp. 7609-7614, 2000.

[156] K. Ishikawa, K. Doh-ura, Y. Kudo et al., "Amyloid imaging probes are useful for detection of prion plaques and treatment of transmissible spongiform encephalopathies," Journal of General Virology, vol. 85, no. 6, pp. 1785-1790, 2004.

[157] P. S. Vassar and C. F. Culling, "Fluorescent stains, with special reference to amyloid and connective tissues," Archives of Pathology, vol. 68, pp. 487-498, 1959.

[158] E. S. Voropai, M. P. Samtsov, K. N. Kaplevskii et al., "Spectral properties of thioflavin $\mathrm{T}$ and its complexes with amyloid fibrils," Journal of Applied Spectroscopy, vol. 70, no. 6, pp. 868874, 2003.

[159] H. Naiki, K. Higuchi, M. Hosokawa, and T. Takeda, "Fluorometric determination of amyloid fibrils in vitro using the fluorescent dye, thioflavine T,' Analytical Biochemistry, vol. 177, no. 2, pp. 244-249, 1989. 
[160] H. Naiki, K. Higuchi, K. Matsushima et al., "Fluorometric examination of tissue amyloid fibrils in murine senile amyloidosis: use of the fluorescent indicator, Thioflavine T," Laboratory Investigation, vol. 62, no. 6, pp. 768-773, 1990.

[161] H. Naiki, K. Higuchi, K. Nakakuki, and T. Takeda, "Kinetic analysis of amyloid fibril polymerization in vitro," Laboratory Investigation, vol. 65, no. 1, pp. 104-110, 1991.

[162] H. LeVine III, "Thioflavine T interaction with synthetic Alzheimer's disease $\beta$-amyloid peptides: detection of amyloid aggregation in solution," Protein Science, vol. 2, no. 3, pp. 404410, 1993.

[163] H. I. LeVine, "Thioflavine T interaction with amyloid beta-sheet structures," Amyloid, vol. 2, no. 1, pp. 1-6, 1995.

[164] L. Cai, R. B. Innis, and V. W. Pike, "Radioligand development for PET imaging of $\beta$-amyloid (A $\beta$ )-current status," Current Medicinal Chemistry, vol. 14, no. 1, pp. 19-52, 2007.

[165] W. E. Klunk, Y. Wang, G.-F. Huang, M. L. Debnath, D. P. Holt, and C. A. Mathis, "Uncharged thioflavin-T derivatives bind to amyloid-beta protein with high affinity and readily enter the brain," Life Sciences, vol. 69, no. 13, pp. 1471-1484, 2001.

[166] C. A. Mathis, B. J. Bacskai, S. T. Kajdasz et al., "A lipophilic thioflavin-T derivative for positron emission tomography (PET) imaging of amyloid in brain," Bioorganic and Medicinal Chemistry Letters, vol. 12, no. 3, pp. 295-298, 2002.

[167] H. Hyare, A. Ramlackhansingh, G. Gelosa et al., "11C-PiB PET does not detect PrP-amyloid in prion disease patients including variant Creutzfeldt-Jakob disease," Journal of Neurology, Neurosurgery \& Psychiatry, vol. 83, pp. 340-341, 2012.

[168] C. A. Mathis, Y. Wang, D. P. Holt, G.-F. Huang, M. L. Debnath, and W. E. Klunk, "Synthesis and evaluation of 11C-labeled 6substituted 2-arylbenzothiazoles as amyloid imaging agents," Journal of Medicinal Chemistry, vol. 46, no. 13, pp. 2740-2754, 2003.

[169] H. F. Kung, C.-W. Lee, Z.-P. Zhuang, M.-P. Kung, C. Hou, and K. Plössl, "Novel stilbenes as probes for amyloid plaques," Journal of the American Chemical Society, vol. 123, no. 50, pp. 1274012741, 2001.

[170] H. F. Kung, M.-P. Kung, Z. P. Zhuang et al., "Iodinated tracers for imaging amyloid plaques in the brain," Molecular Imaging and Biology, vol. 5, no. 6, pp. 418-426, 2003.

[171] N. Okamura, T. Suemoto, H. Shimadzu et al., "Styrylbenzoxazole derivatives for in vivo imaging amyloid plaques in the brain," Journal of Neuroscience, vol. 24, no. 10, pp. 2535-2541, 2004.

[172] K. Ishikawa, Y. Kudo, N. Nishida et al., "Styrylbenzoazole derivatives for imaging of prion plaques and treatment of transmissible spongiform encephalopathies," Journal of Neurochemistry, vol. 99, no. 1, pp. 198-205, 2006.

[173] W. Zhang, S. Oya, M.-P. Kung, C. Hou, D. L. Maier, and H. F. Kung, "F-18 stilbenes as PET imaging agents for detecting $\beta$ amyloid plaques in the brain," Journal of Medicinal Chemistry, vol. 48, no. 19, pp. 5980-5988, 2005.

[174] M. Ono, M. Haratake, M. Nakayama et al., "Synthesis and biological evaluation of (E)-3-styrylpyridine derivatives as amyloid imaging agents for Alzheimer's disease," Nuclear Medicine and Biology, vol. 32, no. 4, pp. 329-335, 2005.

[175] Q. Li, J. Min, Y.-H. Ahn et al., "Styryl-based compounds as potential in vivo imaging agents for $\beta$-amyloid plaques," ChemBioChem, vol. 8, no. 14, pp. 1679-1687, 2007.

[176] A. Cavalli, M. L. Bolognesi, S. Capsoni et al., "A small molecule targeting the multifactorial nature of Alzheimer's disease," Angewandte Chemie, vol. 46, no. 20, pp. 3689-3692, 2007.
[177] S. Bongarzone, H. N. A. Tran, A. Cavalli et al., "Parallel synthesis, evaluation, and preliminary structure-activity relationship of 2,5-diamino-1,4-benzoquinones as a novel class of bivalent anti-prion compound," Journal of Medicinal Chemistry, vol. 53, no. 22, pp. 8197-8201, 2010.

[178] K. Kuwata, N. Nishida, T. Matsumoto et al., "Hot spots in prion protein for pathogenic conversion," Proceedings of the National Academy of Sciences of the United States of America, vol. 104, no. 29, pp. 11921-11926, 2007.

[179] S. B. Raymond, A. T. N. Kumar, D. A. Boas, and B. J. Bacskai, "Optimal parameters for near infrared fluorescence imaging of amyloid plaques in Alzheimer's disease mouse models," Physics in Medicine and Biology, vol. 54, no. 20, pp. 6201-6216, 2009.

[180] R. Chongzhao, X. Xiaoyin, S. B. Raymond et al., "Design, synthesis, and testing of difluoroboron-derivatized curcumins as near-infrared probes for in vivo detection of amyloid- $\beta$ deposits," Journal of the American Chemical Society, vol. 131, no. 42, pp. 15257-15261, 2009.

[181] A. Schmidt and J. Pahnke, "Efficient near-infrared in vivo imaging of amyoid-beta deposits in Alzheimer's disease mouse models," Journal of Alzheimer's Disease, vol. 30, pp. 651-664, 2012.

[182] S. B. Raymond, J. Skoch, I. D. Hills, E. E. Nesterov, T. M. Swager, and B. J. Bacskai, "Smart optical probes for near-infrared fluorescence imaging of Alzheimer's disease pathology," European Journal of Nuclear Medicine and Molecular Imaging, vol. 35, no. 1, pp. S93-S98, 2008. 

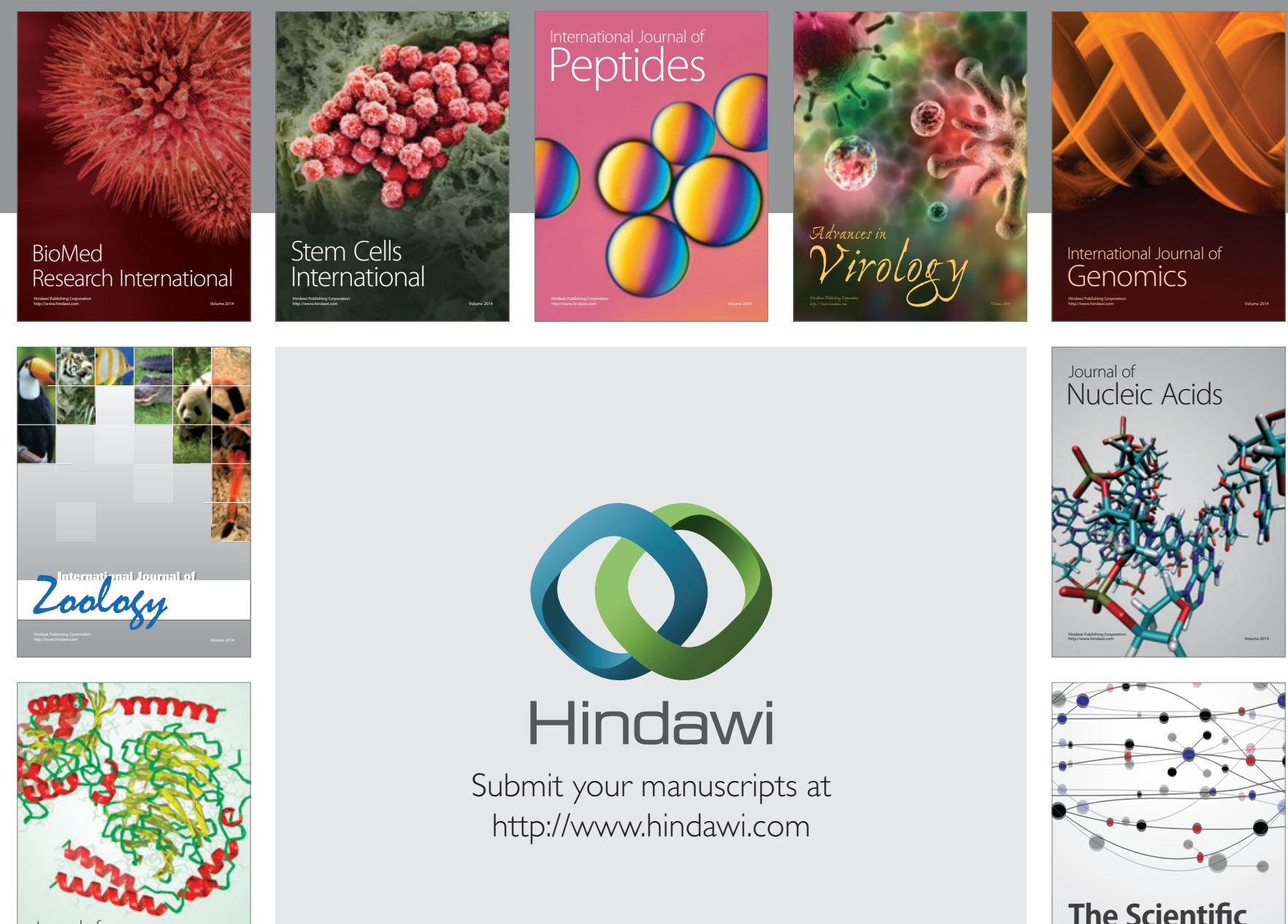

Submit your manuscripts at

http://www.hindawi.com

Journal of
Signal Transduction
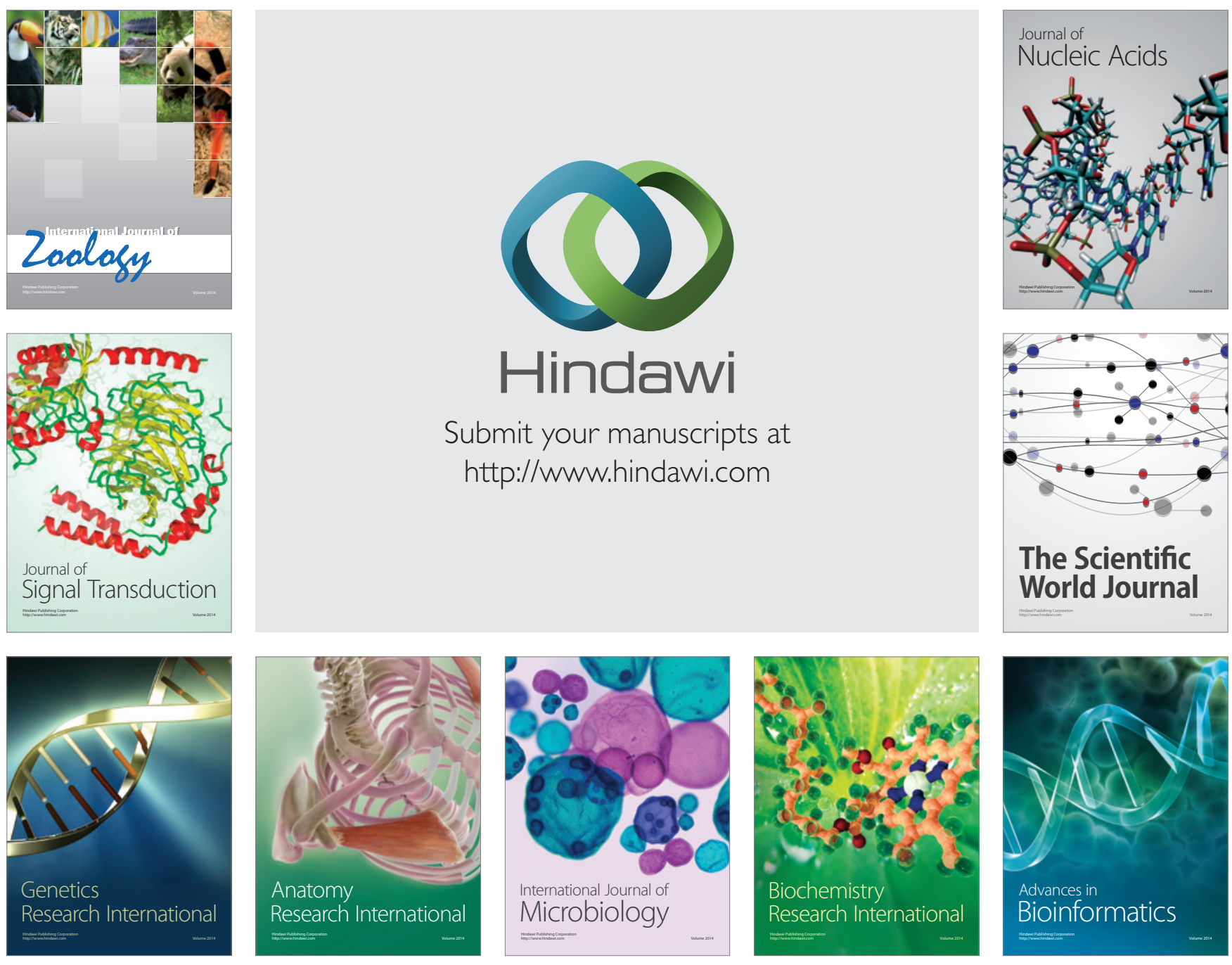

The Scientific World Journal
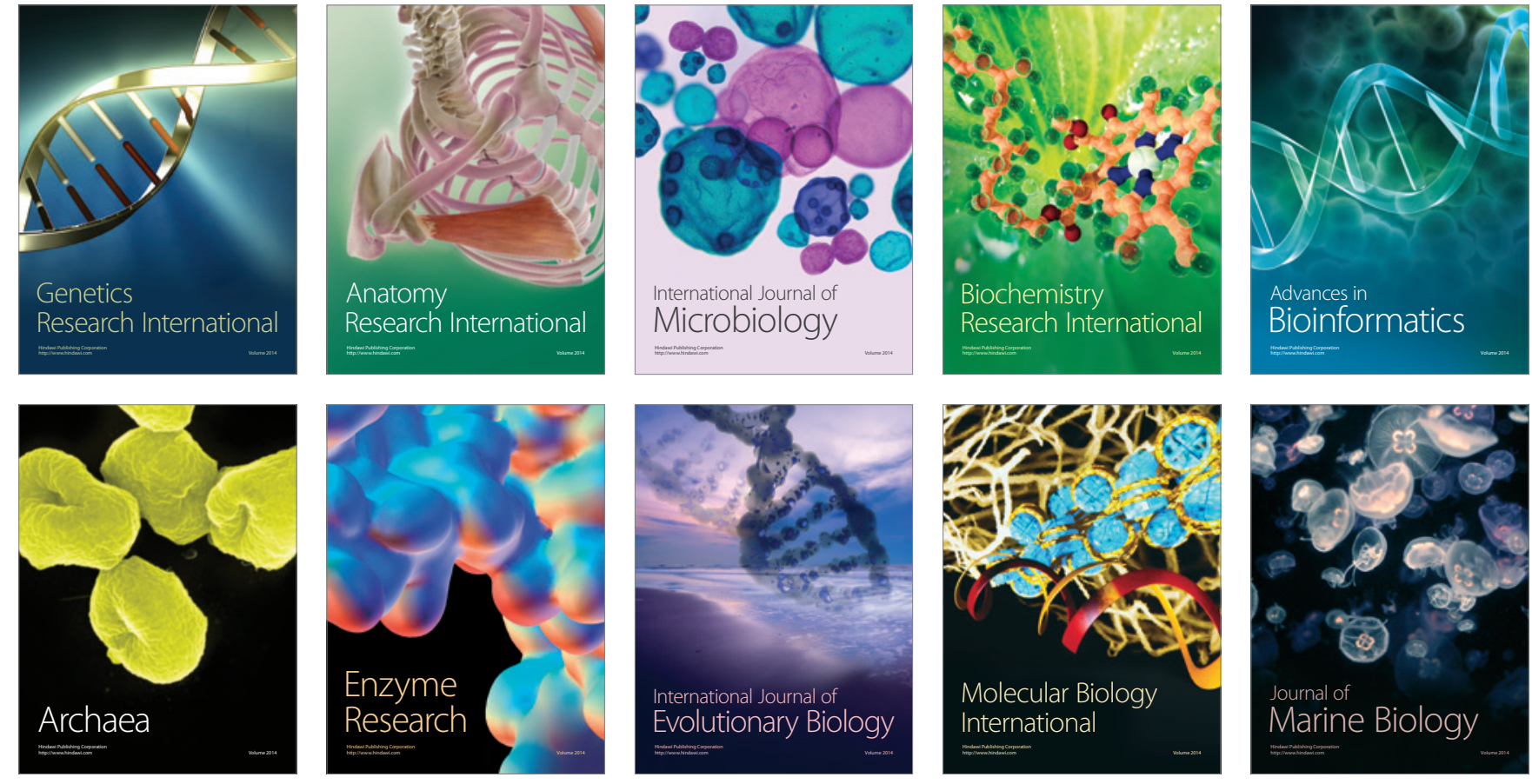